\title{
Scraping hide in the early Upper Paleolithic: Insights into the life and function of the Protoaurignacian endscrapers at Fumane Cave
}

\author{
Alessandro Aleo ${ }^{1,2}\left(\mathbb{D} \cdot\right.$ Rossella Duches $^{3} \cdot$ Armando Falcucci $^{4}\left(\mathbb{D} \cdot\right.$ Veerle Rots $^{5}(\mathbb{D}) \cdot$ Marco Peresani $^{1,6}$ P $^{-}$
}

Received: 14 February 2021 / Accepted: 20 May 2021 / Published online: 17 July 2021

(c) The Author(s) 2021

\begin{abstract}
Endscrapers are specialized tools that are usually recovered in great quantities in every Upper Paleolithic site in Europe. Although they make their first ephemeral appearance in the Middle-late Middle Paleolithic transitional technocomplexes, endscrapers commonly appear in toolkits from initial and early Upper Paleolithic traditions onwards. Nevertheless, endscrapers and, in general, domestic tools have attracted relatively little attention in debates revolving around the significance of technological change, tool function, and tool specialization after the end of the Middle Paleolithic. With the aim to overcome this paucity of information, here, we present the results of a techno-functional study performed on the large endscraper assemblage recovered from the early and late Protoaurignacian layers at Fumane Cave in northeastern Italy. We analyzed these artifacts using technological, morpho-metrical, typological, and functional approaches. Despite the large morphological variability, use-wear traces reveal functional consistency and high levels of specialization for these tools. Almost all the use-wear traces we recorded developed from hide working with transverse motion. Moreover, we find no evidence that endscrapers were involved in the production of bone and antler tools during the late Protoaurignacian. Macroscopic and microscopic wear on the lateral edges of tools point to a considerable number of hafted endscrapers, which implies systematic time investment and planning depth. Comparison with the few endscrapers from transitional industries that have been analyzed highlights marked differences in the production, morphology, and use of these tools and reinforces our view of the Aurignacian as a complex not directly related with preceding European traditions.
\end{abstract}

Keywords Endscraper $\cdot$ Technology $\cdot$ Use-wear traces $\cdot$ Hafting $\cdot$ Aurignacian $\cdot$ Italy

Marco Peresani

marco.peresani@unife.it

1 Dipartimento Di Studi Umanistici, Sezione di Scienze Preistoriche e Antropologiche, Corso Ercole I d'Este, 32, 44100 Ferrara, Italy

2 Faculty of Mechanical, Maritime and Materials Engineering, Delft University of Technology, 2628 CD Delft, The Netherlands

3 MUSE - Museo delle Scienze, Corso del Lavoro e della Scienza 3, 38123 Trento, Italy

4 Department of Early Prehistory and Quaternary Ecology, University of Tübingen, Schloss Hohentübingen, D-72070 Tübingen, Germany

5 Maitre de Recherches du F.R.S.-FNRS, TraceoLab, University of Liège, Place du 20-août 7 (Bât. A4), 4000 Liège, Belgium

6 Istituto di Geologia Ambientale e Geoingegneria, Consiglio Nazionale delle Ricerche, Piazza della Scienza 1, 20126 Milano, Italy

\section{Introduction}

The emergence of the Upper Paleolithic in Eurasia is traditionally considered to have been an abrupt rupture with the Middle Paleolithic that occurred between 48 and $39 \mathrm{ky} \mathrm{cal}$ BP, when Neanderthal populations were replaced by anatomically modern humans (Fu et al. 2016; Higham et al. 2014; Hublin et al. 2020). This first spread of anatomically modern humans (hereafter AMH) is associated with the appearance of the initial Upper Paleolithic (hereafter IUP) (Kuhn and Zwyns 2014), Uluzzian, and Aurignacian cultural units, marking an abrupt change in many aspects of human beings like sociality, communication, economy, and technology, and coinciding with clear-cut implications on the design of stone tool sets. Complexity increased, as well as specialization and standardization, in toolkits, traits generally considered hallmarks of modern behavior (Bar-Yosef 2002; Mellars 2011, 2004; Teyssandier 2008). 
Paleolithic sites offer an abundance of tools made from a variety of organic and inorganic raw materials. In many cases, however, their exact use and function are still scarcely understood in that the typological system used by archaeologists is insufficient to reconstruct past behaviors. A technological and functional examination of stone tools is therefore necessary to comprehend the role played by stone artifacts in the changes associated with the beginning of the Upper Paleolithic. Previous functional studies performed on early Upper Paleolithic (hereafter EUP) assemblages highlighted the importance of rethinking the traditional concept of tooltype (Hardy et al. 2008; Hays and Lucas 2000). The relationship between stone artifact form and function is variable and often context-dependent (Tomáŝková 2005) in relation to behaviors such as use duration, resharpening, and reshaping.

Specialized Upper Paleolithic stone tools, and specifically endscrapers, are an ideal subject for exploring these issues. Endscrapers make their first systematic appearance in EUP complexes like the Châtelperronian, Bohunician, and Uluzzian (Djindjan et al. 1999; Palma di Cesnola 1989; Pelegrin and Soressi 2007; Škrdla 2017). They mark an abrupt rupture with the preceding Middle Paleolithic tradition, which is characterized by the manufacture of different side scraper types like single-edged scrapers, double and convergent scrapers, transverse scrapers, and Quina and demi-Quina scrapers among the most common (Bordes 1961). Endscrapers are also a systematic component of the common tool assemblages in the subsequent periods: the Protoaurignacian and Aurignacian. Despite the high frequency in which they occur in IUP and EUP industries, they have attracted relatively little scientific attention. Endscrapers' function as specialized tools for processing soft animal materials is often inferred without sufficient supporting information from functional analysis. Detailed examinations may reveal a wide range of activities or task specialization depending, among other factors, on site function and environmental setting (Andrefsky 1997). Besides, evidence of hafting traces on a tool category where hafting is not a prerogative for use sheds light on deliberate choices of hunter-gatherers regarding technological strategies, tool design, and tool curation (Rots 2005; Taipale 2019). A techno-functional reexamination of these artifacts, beyond stone-tool typology, will further strengthen our understanding of cultural innovations among AMH hunter-gatherers and help develop criteria to distinguish and recognize their adaptive success.

Roughly two hundred endscrapers have been found in the early and late Protoaurignacian layers at Fumane Cave in northeastern Italy. With its detailed stratigraphic sequence ranging from the Middle to the Upper Paleolithic, including the Uluzzian, Fumane represents a key site for investigating different aspects of the Middle to Upper Paleolithic transition (hereafter MP-UP transition). The cave is one of the best-known and well-dated EUP sites in Europe and preserves traces of intense and repeated human occupation (see references in Sect. 2.1). The abundance and variability of stone tools, most of them recovered at optimal state of preservation, offers a unique opportunity to explore past human behavior. Here, we present the results of an extensive analysis of the endscrapers using a combined technofunctional approach designed to shed light on tool manufacture, blank selection, tool shaping, use, and maintenance. Further, this analysis gives us the opportunity to investigate possible relationships between blank morphology and tool type. In this paper, we seek to address the following research questions:

- Are the endscrapers shaped with a recurring and standardized morphology? Is it possible to define a shared set of features defining the Protoaurignacian endscraper?

- Are the Protoaurignacian endscrapers from Fumane designed to perform specific activities, as usually postulated, or are they meant to address different activities?

- How does the production and use of endscrapers in Fumane fit into the context of the Upper Paleolithic in Western Eurasia?

\section{Materials and methods}

\section{The early and late Protoaurignacian at Fumane Cave}

Fumane Cave is located in the Monti Lessini Plateau (Venetian Prealps, northeastern Italy, $45^{\circ} 35^{\prime} 30.52^{\prime \prime}$ Lat. North-10 ${ }^{\circ}$ 54' 18.67" Long East Greenwich). The cave has been meticulously excavated for decades and details are available in numerous publications (Abu-Zeid et al. 2019; Broglio et al. 2003; Broglio and Dalmeri 2005; Higham et al. 2009; López-García et al. 2015; Peresani 2012). A main cave and two associated tunnels preserve a finely layered sedimentary succession spanning the late Middle Paleolithic and the early Upper Paleolithic (macro-units A and D), with features and dense scatters of remains associated with the Mousterian, Uluzzian, and early and late Protoaurignacian (Bertola et al. 2013; Cavallo et al. 2017; Falcucci et al. 2017; Peresani 2012; Peresani et al. 2016).

At the top of the stratigraphic macro-unit A, there are layers A2 and A1. Layer A2 dates the appearance of the Protoaurignacian to $41.2-40.4 \mathrm{ky}$ cal BP (Higham et al. 2009). Its lower boundary with layer A3 is clear and is marked by a dispersion of ocher over a large extent of the area (Cavallo et al. 2017, 2018; Peretto et al. 2004) and by a considerable change in the content of anthropogenic material (Broglio et al. 2009). In the cave entrance, layer A 2 is covered by layer A1, a thin anthropogenic level with horizontal bedding which makes it indistinguishable from A2 in the cave mouth. A2 thus extends throughout the whole cave entrance and 
cave mouth. The latest Protoaurignacian phase is recorded in the macro-unit $\mathrm{D}$ which includes several layers embedded in coarse-sandy sediments. Layers D3a and D3b are the most extended, while layer D6 is a loose stony layer limited to the eastern zone of the cave. Traces of human presence are less dense than in A2-A1; however, hearths and other surface features had been exposed (Broglio et al. 2006).

The most relevant features of the Protoaurignacian lithic industries at Fumane are systematic bladelet production and the dominance of retouched bladelets among tools (Falcucci et al. 2017). Most of the artifacts discarded at the site belong to bladelets and by-products of lamellar reduction strategies. Bladelets are produced from independent reduction strategies that are, in most cases, not related to the reduction of larger blade cores (Falcucci et al. 2017, 2018). Blades of variable morphometric attributes represent the second goal of the lithic production system. The bigger blanks were usually selected to manufacture formal tools, independently of their shape and the presence of cortex. Layers A2-A1 and the ensemble of layers D6-D3 do not show significant differences in the blade and bladelet technologies, while flake production seems to be more systematic in D6-D3 (Falcucci 2018; Falcucci et al. 2020). Most of the flake cores display sets of unidirectional flake scars, removed from different striking platforms, during independent reduction phases (De Stefani et al. 2012; Falcucci et al. 2020).

Ornamental objects represent a regular cultural component of the Aurignacian layers. They consist of grooved red deer incisors and several hundreds of perforated shell beads belonging to over sixty different taxa, most of them marine (Peresani et al. 2019a, b). The bone and antler industries are composed of a variety of tools. Split-based bone points are found only in layers D6 and D3, except one incomplete tool found at the interface between D3 and A1 (Bertola et al. 2013). The same is true for five stones painted with red ocher (Broglio and Dalmeri 2005; Broglio et al. 2009).

\section{The studied sample: quantification and technological approach}

The sample consists of 205 endscrapers, excavated from 1988 to 2006 and in 2014, divided into complete and broken specimens, scraper-head fragments, and fragmented endscrapers with intact functional extremity. We analyzed endscrapers using an integrated techno-morphological and functional approach (Fig. 1). The tools are made from fine to fine-coarse chert of different carbonatic formations collected within $5-15 \mathrm{~km}$ acf from the site. The most exploited are from Maiolica, Scaglia Variegata Alpina, Scaglia Rossa, and Ooliti di San Vigilio formations and in lower extent Jurassic and Tertiary calcarenites (Bertola et al. 2013). Chert is abundant, resulting in low levels of tool reduction recycling (sensu Andrefsky 1994). In this study, we have grouped the endscrapers into two main assemblages. Most of the artifacts $(\mathrm{n}=138)$ come from layers $\mathrm{A} 2$ and A1. A smaller number $(n=67)$ comes from the lower part of the macro-unit $D$, most of them from layers D6 and D3 and a few from layers D1, D2, D5, and D7 (Table 1). We excluded from our analysis several endscrapers from the inner squares of the cave because of their alteration due to post-depositional disturbance, two endscrapers currently on display in the permanent exhibition of the Paleontological and Prehistoric Museum of Sant'Anna d'Alfaedo, and one endscraper currently on display in the permanent exhibition of the Museum of Sciences (MUSE) at Trento.

In this study, we employed a holistic approach, which aims to integrate technological, morpho-metric, and traceological methods. The technological analysis combines two complementary approaches: reduction sequence (Inizan et al. 1995) and attribute analysis (Andrefsky 1998). We created a database to record several discrete and metric attributes, with particular attention devoted to the scraperheads. The metric attributes of each artifact were recorded using a digital caliper and size differences were assessed in IBM SPSS Statistics 24. We performed non-parametric Mann-Whitney because the sample violated the assumption of normality necessary for Shapiro-Wilk and Kolmogorov-Smirnov tests. We recorded the scraper-head width (maximum width of the retouched functional extremity) only on complete specimens, while we excluded from the metric analysis extremely fragmented endscrapers, those with only the functional extremity preserved or fragments of scraperheads. We documented the longitudinal profile for complete and almost complete blanks, to verify a possible relation between tool morphology and its functional efficiency. The longitudinal profile was not recorded in extremely fragmented artifacts and in tools made on flakes with uneven morphologies. We focused particularly on tool orientation, tool morphology, tool cross-section, and retouching of the working edge. In order to examine whether or not the scrapers were used hafted, we documented lateral scars and/or retouch. Besides, we created a specific typological list starting from a simplified version of the primary types defined by G. Laplace (Laplace 1964).

Investigation of reduction intensity has significant implications for reconstructing past human behaviors. Different studies (e.g., Beyries and Cattin 2015; Donahue and Fischer 2015; Jacquier and Naudinot 2015; Loebel 2013; Morales and Vergès 2014; Rots 2005; Shott and Weedman 2007) demonstrated that the combination of stone tool management processes analysis and use-wear observations can contribute to a better understanding of the organization of lithic production, site function, occupation intensity, raw material availability, and exploitation/maintenance. Thus, we documented the presence of resharpening to better understand tool life cycles. Resharpening may occur for different 
Fig. 1 Sample of endscrapers from Fumane (RF) macro-units $\mathrm{A}$ and $\mathrm{D}$. Endscrapers on regular blade $(3,55)$, on blade with lateral scalar retouch $(2,126$, 107), on blade with bladelet scars (17), on flake $(245,164)$, on laminar flake with blade scars (123), on crested blade $(53,31,166)$, on thick cortical flake $(167,52,23)$. Arrows show the direction of the blow. Photos: A. Falcucci and A. Aleo
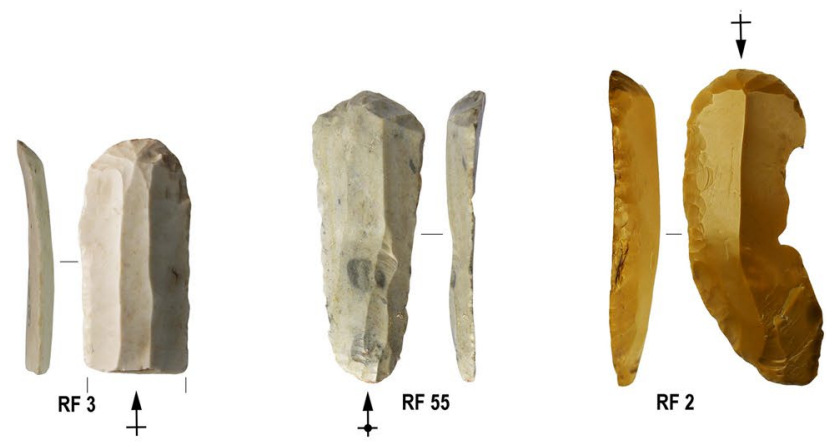

RF 2
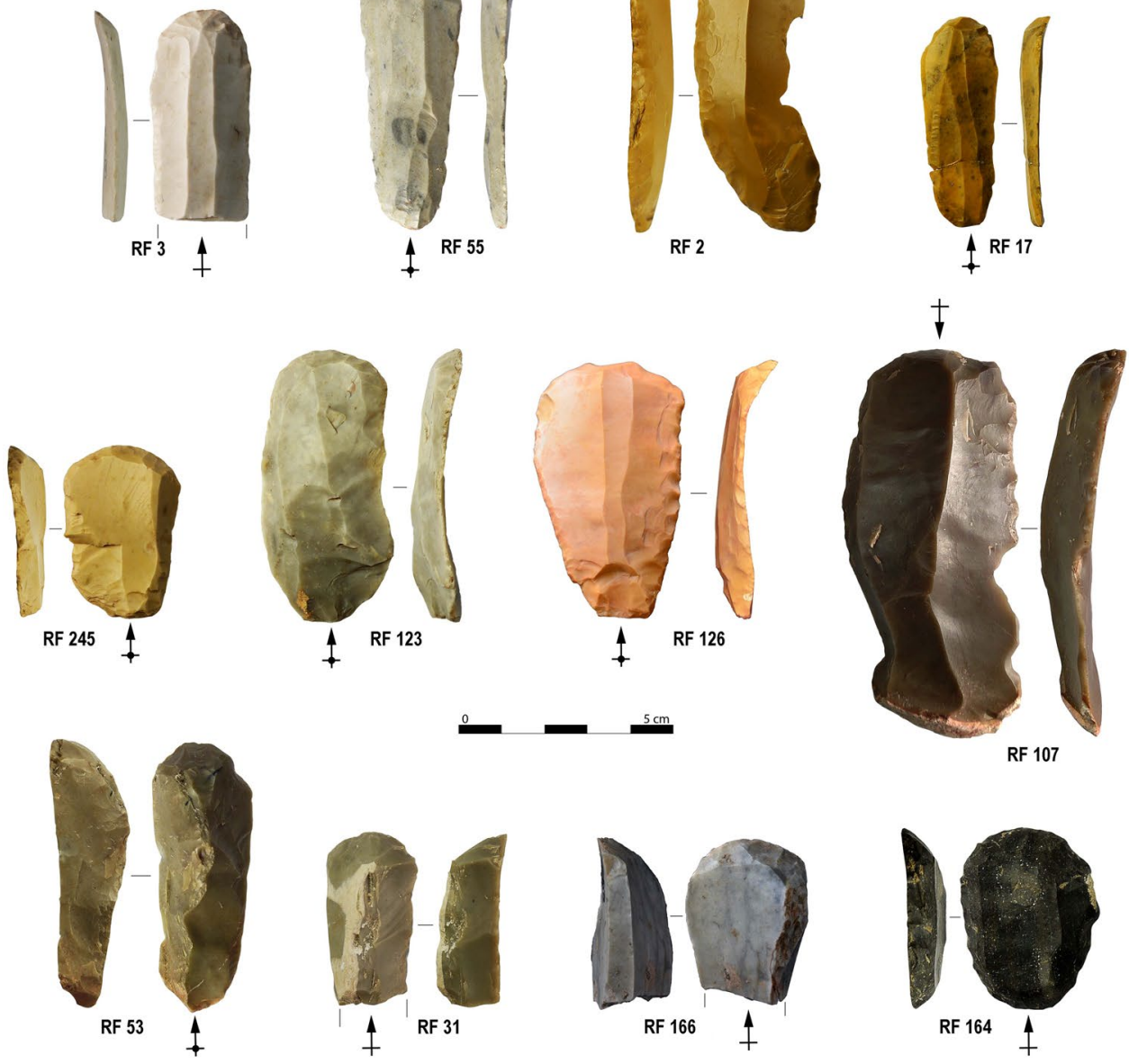

RF 107
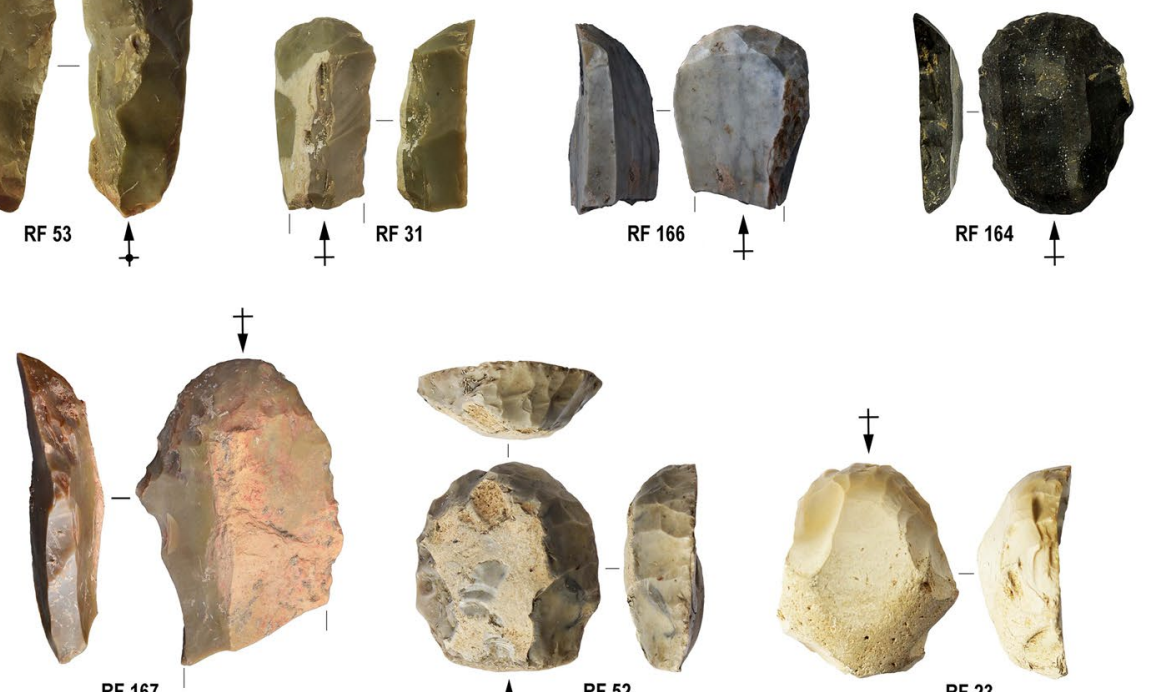

RF 167
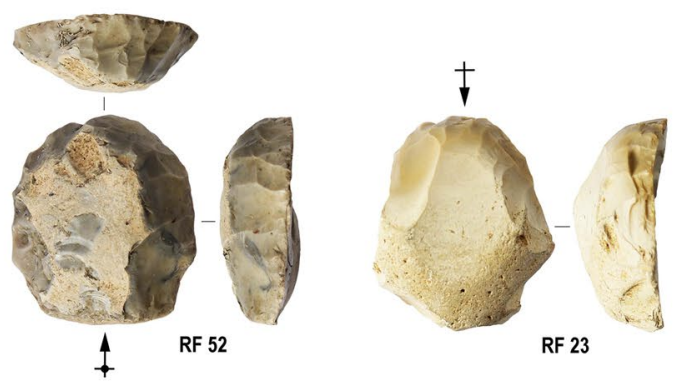

RF 23
Table 1 Distribution of the endscrapers from early and late Protoaurignacian layers from Fumane Cave

\begin{tabular}{|c|c|c|c|c|c|c|c|c|c|c|c|c|c|c|c|}
\hline \multicolumn{3}{|c|}{ Macro-unit A } & \multicolumn{13}{|c|}{ Macro-unit D } \\
\hline A1 & $\mathrm{A} 2$ & $\mathrm{~A} 2 \mathrm{R}$ & D D1 & D2 & D3 & D3 + D6 & D3a & $\mathrm{D} 3 \mathrm{a}+\mathrm{b}$ & D3b & $\mathrm{D} 3 \mathrm{~b} \alpha$ & D3d & D31 & D5 & D6 & D7 \\
\hline 20 & 104 & 14 & 11 & 1 & 1 & 7 & 2 & 5 & 10 & 5 & 11 & 2 & 2 & 18 & 1 \\
\hline \multicolumn{3}{|c|}{ Total 138} & \multicolumn{13}{|c|}{ Total 67} \\
\hline
\end{tabular}

reasons, such as to rejuvenate a tool's edge to restore its efficiency, after an accidental breakage or to modify its morphology. Sharpening aims to restore the working edge of the instrument, probably for the same use for which it was designed. It is, therefore, considered an indicator of maintenance (Morales and Vergès 2014, p. 303). This is 
different from recycling, a process that implies a modification of the tool in order for it to be used for new functions (Schiffer et al. 1981; Shott 1995; Beyries and Cattin 2015; Jacquier and Naudinot 2015). Some tools can be resharpened a great number of times, with a consequent progressive loss of mass. This implies that the artifact's shape changes progressively from the first use to its discard (Bamforth 1986; Blades 2003; Dibble 1997; Frison 1968; Torrence 1989), with a decrease in size and modification in form. It also has consequences for the preservation of functional evidence since each retouching tends to partially remove use-wear and residues (though not hafting wear, cf. Rots 2005). Small flakes potentially from resharpening of the scraper-heads have not yet been analyzed.

We employed technological and functional approaches also for the analysis of a group of carinated pieces from both assemblages to evaluate whether they were endscrapers designed for scraping, as the name implies, or if they were used as specialized cores to produce bladelets. It is also possible to contemplate a recycling or a secondary utilization of these pieces once exhausted as cores. Indeed, the presence of secondary retouching and edge damage leads to the hypothesis that they were used as tools. To understand their function, we documented the morphology of the blank, the length, width, and orientation of the removals. The microscopic examination of the use-wear traces included edge damage, edge modifications, and micro-wear (polish and striations).

\section{Traceological analysis}

For the functional analysis, we detected both macroscopic and microscopic traces with the aid of a Zeiss stereomicroscope Stemi 2000C with an external light source and magnifications up to $\times 56$ and a Zeiss Vario metallurgical microscope with incident light and bright-field illumination using magnifications up to $\times 500$. The analysis was carried out at the TraceoLab of the University of Liège. Observations under a stereomicroscope are particularly helpful in the identification of the relative hardness of the worked material and the use motion (Odell 1977; Semenov 1964; Tringham et al. 1974) on the basis of the characteristics and distribution patterns of edge damage, rounding, polish, and striations. Higher magnifications (up to $\times 500$ ) using incident light allow for detailed observations of polishes, rounding, striations, and edge damage, enabling more exact identification of the worked material and the use motion (Keeley 1980; Keeley and Newcomer 1977). Attention was devoted to the combination of different trace types, as well as their distribution and patterning over the edges and surfaces of the tools in relation to technological features. We interpreted the tools within the context of their life cycle and evaluated in detail any potential evidence of resharpening and hafting (cf. Rots 2003, 2009, 2010a, b, 2013; van Gijn 2010). Such an approach allows for an improved understanding of Paleolithic assemblages and human behavior (Rots 2003, 2005).

We based the interpretations of the wear traces on an experimental reference collection that is representative of a broad range of use activities and other potential trace causes (knapping, retouch, hafting, trampling, etc.) (e.g., Rots 2010a, 2010b). Archaeological wear traces observed on Fumane endscrapers were visually compared with the ones on the experimental tools and pictures of the most significant evidence of use were taken. The large experimental collection available at the TraceoLab at the University of Liège consists of more than 4000 stone tools. It categorizes a large variety of scrapers based on their use for different activities, including a large-scale experimental set specifically related to hide working (118 tools). The experimental tools embrace a range of fine to coarse-grained raw materials that is representative of the differences in roughness and texture characterizing our archaeological sample. The reference collection also includes a broad range of stone tools used in various hafting arrangements, which aids in the identification of these practices in archaeological assemblages following the methodology designed in earlier studies (Rots 2003, 2010a; Rots et al. 2001, 2006).

Attention was also devoted to residues but given that the material had been washed and handled long after the excavation campaigns for previous typological analyses, only strongly adhering residues were considered (Cnuts et al. 2018). Residue analysis is still ongoing and will be not addressed here.

The state of preservation was evaluated systematically and even though alterations were observed, these mostly consisted of a light general polishing that did not hinder the functional analysis and did not prevent accurate observations or interpretations. Also, thermal alterations were observed, but those could be so intense as to make a functional analysis impossible. Such tools were excluded from more detailed analysis.

After the excavation, the tools were stored in individual plastic/paper bags to ensure minimal contact between artifacts. Only a few endscrapers were identified in a later stage of the analysis of the lithic assemblage and sorted from large plastic bags where they were stored with other flint implements. Post-excavation damage was thus minimal and did not affect the functional interpretation.

Prior to the functional analysis, we cleaned all endscrapers with tap water to remove any post-depositional deposits. During the analysis under high magnification, we cleaned the tools with cotton pads soaked with ethanol and/or acetone in order to remove grease from handling or other residues that hinder observation of the wear phenomena on tool edges. In some cases, the tools were immersed in water in an ultrasonic tank (Elmasonic) for $10 \mathrm{~min}$ to remove strongly adhering sediment from the edges of the tool. 
All the functional observations were entered in a database that records the state of preservation of the tools, presence or absence of edge rounding, polish, striations, residues, and the presence of resharpening. We inferred the worked materials and the use motions from the different attributes of the use-wear. Depending on the combination of the aforementioned evidence, we attempted to class the tools based on the intensity of the wear traces observed. The degree of wear varies from poorly to heavily developed. Schematic drawings of the tools showing the location and distribution of use traces were also made during the microscopic analysis.

\section{Results}

\section{Technological, typological, and morphometric features of the tools}

Table 2 summarizes the frequency of the main blank types across macro-units $\mathrm{A}$ and $\mathrm{D}$ and provides a technological overview for each class. Laminar products are more common in layers A2 and A1, while in layers of macro-unit D flake blanks clearly increase in frequency. This is not surprising since the overall frequency of flakes is higher in macro-unit D. Flake production is more important in the late Protoaurignacian of Fumane Cave, where flake cores show, in some cases, a degree of predetermination that was not found in the early Protoaurignacian (Falcucci et al. 2020). It is also evident that Protoaurignacian knappers selected those blanks with desired morphometric features, whether they came from the optimal production phase or from the initialization and maintenance phases carried out on bladelet and blade cores (Falcucci et al. 2017).

Table 2 Distribution of blank types

\begin{tabular}{lllll}
\hline Blank types & $\mathrm{A}$ & $\%$ & $\mathrm{D}$ & $\%$ \\
\hline Blade & $\mathbf{7 5}$ & $\mathbf{5 4 . 3}$ & $\mathbf{2 7}$ & $\mathbf{4 0 . 3}$ \\
Non-cortical & 40 & 53.3 & 13 & 48.1 \\
Cortical & 2 & 2.7 & 0 & 0 \\
Semi-cortical & 15 & 20 & 8 & 29.6 \\
Crested & 9 & 12 & 1 & 3.7 \\
Maintenance & 9 & 12 & 5 & 18.5 \\
Bladelet & $\mathbf{1}$ & $\mathbf{0 . 7}$ & $\mathbf{0}$ & $\mathbf{0}$ \\
Flake & $\mathbf{5 9}$ & $\mathbf{4 2 . 8}$ & $\mathbf{3 9}$ & $\mathbf{5 8 . 2}$ \\
Non-cortical & 27 & 45.8 & 11 & 28.2 \\
Cortical & 4 & 6.8 & 3 & 7.7 \\
Semi-cortical & 18 & 30.5 & 17 & 43.6 \\
Crested & 2 & 3.4 & 1 & 2.6 \\
Maintenance & 8 & 13.6 & 7 & 17.9 \\
Undetermined & $\mathbf{3}$ & $\mathbf{2 . 2}$ & $\mathbf{1}$ & $\mathbf{1 . 5}$ \\
Total & $\mathbf{1 3 8}$ & $\mathbf{1 0 0 . 0}$ & $\mathbf{6 7}$ & $\mathbf{1 0 0 . 0}$ \\
\hline
\end{tabular}

Endscraper types are listed in Table 3. Single endscrapers, made on blades or flakes, are the most numerous tools in both units. In layers A 2 and $\mathrm{A} 1$, single endscrapers made on thin blanks prevail on thick ones, while in layers of macrounit $\mathrm{D}$, the number of tools made on thick blanks is higher. Nosed and carinated endscrapers are rarely represented in both samples. As Table 3 shows, the frequency of carinated endscrapers slightly increases in macro-unit $\mathrm{D}$.

In both assemblages, the most common profiles are convex and slightly convex, while intense curved blanks are rare. Straight profiles are also common among blades. Only a small number of endscrapers display sinuous and twisted profiles. Their percentage is lower than $10 \%$ in A, while in $\mathrm{D}$, the number of twisted blanks is around $15 \%$. Twisting is slightly pronounced in all specimens (see Table 4).

Table 5 summarizes all relevant metric values of the endscrapers. The selection of varied blank types belonging to different phases of core reduction sequences (Falcucci et al. 2017) explains the remarkable difference in the range of values within each assemblage (Fig. 2). Although laminar blanks are less common in $\mathrm{D}$, there are no significant

Table 3 Inventory of endscraper types

\begin{tabular}{llcll}
\hline Type & $\mathrm{A}$ & $\%$ & $\mathrm{D}$ & $\%$ \\
\hline Single on thin blade/flake & 52 & 37.7 & 18 & 26.9 \\
Single on thick blade/flake & 25 & 18.1 & 22 & 32.8 \\
Double & 3 & 2.2 & 0 & 0 \\
On retouched thin blade/flake & 12 & 8.7 & 4 & 6 \\
On retouched thick blade/flake & 5 & 3.6 & 4 & 6 \\
Circular & 2 & 1.4 & 0 & 0 \\
Flat-nosed & 6 & 4.3 & 2 & 3 \\
Thick-nosed & 1 & 0.8 & 1 & 1.5 \\
Carinated & 8 & 5.8 & 7 & 10.4 \\
Endscraper-burin & 6 & 4.3 & 1 & 1.5 \\
Endscraper-splintered piece & 1 & 0.8 & 1 & 1.5 \\
Undetermined & 17 & 12.3 & 7 & 10.4 \\
Total & $\mathbf{1 3 8}$ & $\mathbf{1 0 0 . 0}$ & $\mathbf{6 7}$ & $\mathbf{1 0 0 . 0}$ \\
\hline
\end{tabular}

Table 4 Longitudinal profile curvature categories for flakes/blades. Profile was not recorded in extremely fragmented artifacts and in tools made on flakes with uneven morphologies

\begin{tabular}{llllr}
\hline Longitudinal profile & $\mathrm{A}$ & $\%$ & $\mathrm{D}$ & \multicolumn{1}{c}{$\%$} \\
\hline Convex & 23 & 16.6 & 5 & 7.5 \\
Slightly convex & 29 & 21 & 26 & 38.8 \\
Sinuous & 11 & 8 & 10 & 14.9 \\
Straight & 19 & 13.8 & 6 & 8.9 \\
Twisted & 12 & 8.7 & 5 & 7.5 \\
Undetermined & 44 & 31.9 & 15 & 22.4 \\
Total & $\mathbf{1 3 8}$ & $\mathbf{1 0 0 . 0}$ & $\mathbf{6 7}$ & $\mathbf{1 0 0 . 0}$ \\
\hline
\end{tabular}


Table 5 Metric maximal values (in millimeters) of the studied endscrapers. Macro-units A and D values are given in the same column to allow a direct comparison. Endscrapers' extremities were excluded from the metrical analysis. Scraper-head width was recorded only in specimens with intact working edge. Measures are given in millimeters.

\begin{tabular}{|c|c|c|c|c|c|c|c|c|c|c|c|c|}
\hline & \multicolumn{2}{|c|}{ Number } & \multicolumn{2}{|l|}{ Range } & \multicolumn{2}{|c|}{ Average } & \multicolumn{2}{|c|}{ Mode } & \multicolumn{2}{|c|}{ Median } & \multicolumn{2}{|l|}{ SD* } \\
\hline & $\mathrm{A}$ & $\mathrm{D}$ & $\mathrm{A}$ & $\mathrm{D}$ & $\mathrm{A}$ & $\mathrm{D}$ & $\mathrm{A}$ & $\mathrm{D}$ & A & $\mathrm{D}$ & A & $\mathrm{D}$ \\
\hline Length & 120 & 60 & $20-119$ & $22-84$ & 46.2 & 45.2 & 35 & 43 & 44 & 45 & 15.3 & 12.5 \\
\hline Width & 120 & 60 & $11-49$ & $15-46$ & 26.7 & 28.1 & 18 & 33 & 26 & 27 & 7.4 & 7.1 \\
\hline Scraper-head width & 104 & 56 & $8-38$ & $12-41$ & 23.2 & 25 & 20 & 30 & 23 & 25.5 & 6.7 & 6.9 \\
\hline Thickness & 120 & 60 & $4-24$ & $3-23$ & 9.6 & 10.8 & 8 & 7 & 6 & 11 & 4.2 & 4.4 \\
\hline
\end{tabular}

* SD standard deviation
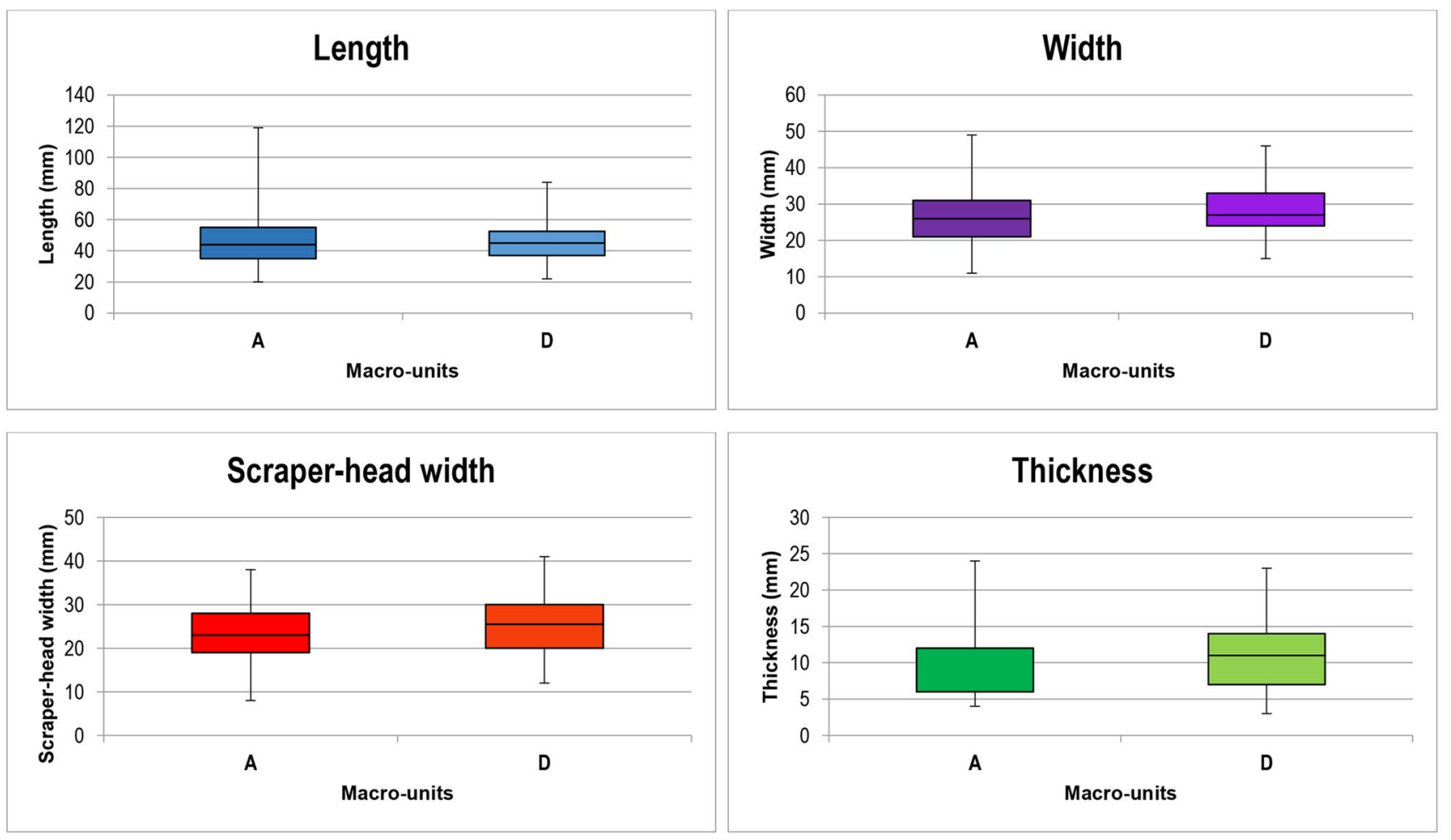

Fig. 2 Box-plots of metric values (in millimeters) of the endscrapers from Fumane (RF) macro-units A and D. Broken endscrapers with only the functional extremity preserved were excluded. Scraper-head width was recorded only in specimens with complete working edge

differences in the distribution of length (Mann-Whitney $\mathrm{U}=3593, \mathrm{p}=0.9$ ) and width (Mann-Whitney, $\mathrm{U}=2978$, $\mathrm{p}=0.06$ ) values when directly compared with A. Endscrapers from D are, however, significantly thicker (Mann-Whitney, $\mathrm{U}=2638.5, \mathrm{p}<0.01$ ). Interestingly, scraper-heads are slightly broader in D (Mann-Whitney, $\mathrm{U}=2607.5, \mathrm{p}<0.01)$, despite the similarity in the overall width of tools' blanks. This difference might reflect a specific functional specialization of these tools; they may have been used to work different materials or they may have carried out various activities. Through the subsequent functional examination of all the endscrapers, we attempt to test this hypothesis.
Figure 3 shows the distribution of length/width ratios and thickness values for complete endscrapers considered whole. Endscrapers can be divided into three groups: (i) the homogenous group of endscrapers made on blades from the optimal production phase, characterized by reduced thickness ranging $0.5 \mathrm{~cm}$ up to $0.7 \mathrm{~cm}$ in most cases and variable length/width ratio influenced by the presence of both intact and almost complete blades; (ii) the group of endscrapers made on by-products from the initialization and maintenance phases of blade and flake cores, characterized by the highest metric variability, as demonstrated by length/width ratios ranging from 1.56 to $4.35 \mathrm{~cm}$ and thicknesses ranging from 0.4 to $1.7 \mathrm{~cm}$; (iii) the group of endscrapers on flakes 
Fig. 3 Distribution of length/ width ratio (elongation index$y$-axis) and thickness values (in millimeters- $\mathrm{x}$-axis) for the endscrapers on complete and fragmented blade (red), complete and fragmented byproduct (blue), complete and fragmented flake (green) from Fumane (RF) macro-units A and D. Endscrapers with postdepositional fractures and broken endscrapers with only the functional extremity preserved were excluded

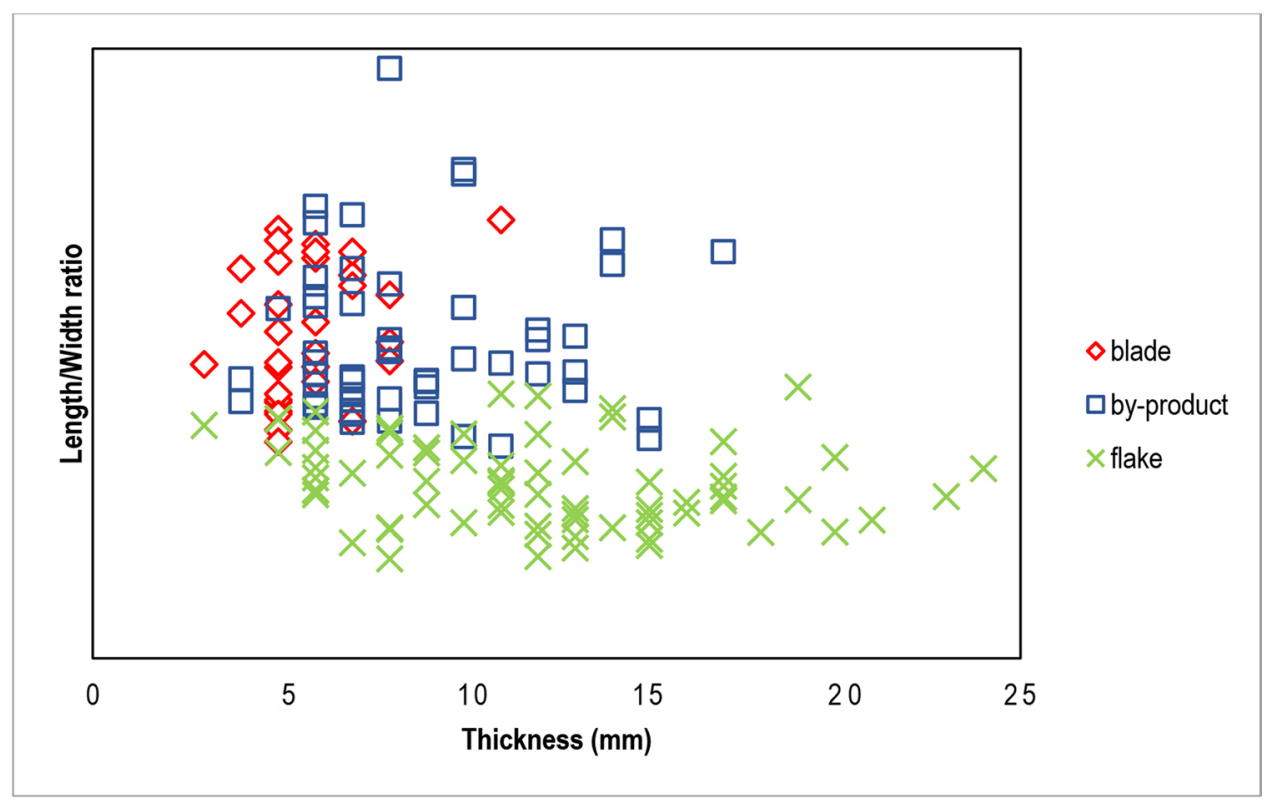

characterized by a length/width ratio always lower than $2 \mathrm{~cm}$ and a wide thickness ranging from 0.3 to $2.4 \mathrm{~cm}$.

\section{Morphological attributes of the scraper-heads}

Almost all the endscrapers display a single scraper-head located in both the distal and proximal part of the blank. Only three endscrapers from A display a double scraperhead, which means that both blank's extremities were modified by retouch into scraper-heads. The total number of scraper-heads we analyzed is 208: 141 for A and 67 for D.

Table 6 summarizes the main morphological attributes of the analyzed scraper-heads. Over half of the specimens have their working edge on the distal extremity, while only $20 \%$ have working edges on the proximal part. Convex, oblique, and irregular morphologies are represented most often, with most being convex. The possible relationship between a specific scraper-head morphology and different materials must be microscopically verified.

We recorded evidence of resharpening of the functional extremity for 184 (88\%) endscrapers from both A and D. One tool does not show any traces of resharpening, while we classified 23 as undetermined because of the high post-depositional alteration of the surface and edges. At a macroscopic level, intense resharpening may cause a variation in the curvature or shape of the scraper-head. The presence of stepped or hinged small scars overlapping one another on the dorsal face of the retouched edge marks another evidence allowing us to identify multiple resharpening attempts (Fig. 4). Scraper-heads with plano-convex longitudinal cross-sections are the most abundant $(65 \%)$. This may be linked to the intense degree of resharpening observed. Repeated resharpening sessions caused the scraper-head to recede and its edge angle to increase. These scraper-heads are characterized by a semi-abrupt and crossed-abrupt retouch and an average angle of $54.8^{\circ}$. Twenty-nine percent of the scraper-heads exhibit a concave-convex (en concorde) longitudinal crosssection. This shape results in a slightly curved profile of the working edge, which may provide better contact with the worked material. The scraper-head has mostly a semiabrupt, low-angle retouch. Evidence of resharpening was recognized also on these tools, but the removal of invasive retouch flakes maintained a low edge angle, averaging $43.4^{\circ}$.

\section{Evidence of use}

We first examined the whole assemblage (constitute of 205 endscrapers) under low magnification to evaluate whether the tools showed signs of use. Scars, edge rounding, striations, and polish were systematically documented when visible. Based on this first analysis, an evaluation of potential evidence of hafting and resharpening was also made. Our functional hypotheses were further systematically tested under high magnification. Overall, most endscrapers proved to be affected by some degree of post-depositional alteration. This alteration may consist of a gentle general polishing to an intensive alteration polish, generally associated with rounding, that hinders straightforward identification and interpretation of the traces of use (Levi Sala 1986). Moreover, we observed damage from exposure to fire or heat. For tools affected by minor thermal alterations, we were able to confidently interpret use-wear traces (cf. Rutkoski et al. 2020). When thermal alterations were more important, no wear analysis was possible. In some cases, damage and metal scratches from contact with excavation equipment could be observed as well, but generally did not 
Table 6 Distribution of the main morphological attributes of the analyzed scraper-heads

\begin{tabular}{|c|c|c|c|c|}
\hline Scraper-head & $\mathrm{A}$ & $\%$ & $\mathrm{D}$ & $\%$ \\
\hline \multicolumn{5}{|l|}{ Position } \\
\hline Axial-distal & 70 & 49.7 & 36 & 53.7 \\
\hline Distal & 21 & 14.9 & 10 & 14.9 \\
\hline Axial-proximal & 14 & 9.9 & 5 & 7.5 \\
\hline Proximal & 14 & 9.9 & 9 & 13.4 \\
\hline Dejetè & 3 & 2.1 & 2 & 3 \\
\hline Lateral & 5 & 3.6 & 3 & 4.5 \\
\hline Continuous & 4 & 2.8 & 0 & 0 \\
\hline Undetermined & 10 & 7.1 & 2 & 3 \\
\hline \multicolumn{5}{|l|}{ Morphology } \\
\hline Convex & 46 & 32.6 & 15 & 22.4 \\
\hline Slightly convex & 8 & 5.7 & 7 & 10.4 \\
\hline Oblique & 27 & 19.1 & 8 & 11.9 \\
\hline Slightly oblique & 9 & 6.4 & 3 & 4.5 \\
\hline Straight & 7 & 5 & 3 & 4.5 \\
\hline Irregular & 27 & 19.1 & 17 & 25.4 \\
\hline Irregular-pointed & 5 & 3.6 & 6 & 9 \\
\hline Undetermined & 12 & 8.5 & 8 & 11.9 \\
\hline \multicolumn{5}{|l|}{ Cross-section } \\
\hline Plano-convex & 93 & 66 & 42 & 62.7 \\
\hline En concorde & 39 & 27.6 & 21 & 31.3 \\
\hline Undetermined & 9 & 6.4 & 4 & 6 \\
\hline \multicolumn{5}{|l|}{ Retouch } \\
\hline Abrupt & 11 & 7.8 & 2 & 3 \\
\hline Crossed-abrupt & 18 & 12.8 & 9 & 13.4 \\
\hline Semi-abrupt & 94 & 66.6 & 40 & 59.7 \\
\hline Low & 9 & 6.4 & 12 & 17.9 \\
\hline Undetermined & 9 & 6.4 & 4 & 6 \\
\hline \multicolumn{5}{|l|}{ Resharpening } \\
\hline Yes & 129 & 91.5 & 55 & 82.1 \\
\hline No & 0 & 0 & 1 & 1.5 \\
\hline Undetermined & 12 & 8.5 & 11 & 16.4 \\
\hline Total & 141 & 100.0 & 67 & 100.0 \\
\hline
\end{tabular}

prevent the interpretation of the use-related wear traces. For all tools, we evaluated the alteration intensity on a relative scale from 0 (unaltered) to 4 (heavily affected by alteration). We excluded 14 endscrapers from high magnification analysis due to intense post-depositional alterations. These tools did not display any trace of use during the initial screening under the stereomicroscope. Serious heat damage, general rounding, and extended alteration polish have likely obliterated any potential original trace of use. Therefore, 191 endscrapers were analyzed under high magnification.

Following the first observations under low magnification and the follow-up under high magnification, tools were also classified with regard to hafting and the hafting technique. As a result, a small sample of endscrapers $(\mathrm{n}=11)$ was selected for more detailed analysis to tentatively interpret the hafting arrangement used.

Endscrapers proved to be predominantly used for working hides, even though traces of use were variably developed and ranged from poorly to heavily developed. In the poorly developed stage, we usually cannot interpret traces with certainty. The same holds for endscrapers that were heavily affected by alterations. In the latter cases, edge rounding was generally still visible, which is a typical feature of hide use-wear but cannot be considered a reliable identifier of a hide working activity, in itself, as other processes or uses can also produce this feature. However, we could make more reliable interpretations when we could observe rounding in combination with a hide working polish (rough texture, poorly reflective or dull, intrusive, cf. Keeley 1980; Vaughan 1985) and/or striations. Striations were systematically oriented perpendicular to the scraper edge, implying the orientation of the tool during scraping.

We documented resharpening wear on most of the tools. A distinction between resharpening and macro-wear traces is generally possible since resharpening interrupts and removes use-wear evidence, which results in a distinct differential development of the use traces between the resharpened and non-resharpened parts (Rots 2010a, b). Moreover, we also observed striations linked to resharpening processes, and in several cases, we were able to identify bone as the hammer used (Rots 2010b). Striations from retouch are associated with the concavity that results from the removal of a retouch flake (Fig. 5: RF 18). These negatives typically cut through the use-wear if the tool was discarded during resharpening because it was either unsatisfactory or caused a fracture in the tool or tool edge. Even when resharpening could be completed and a subsequent use session took place, evidence of use could still occasionally be observed based on the presence of retouch striations (that differ from those related to hide working).

Table 7 summarizes the distribution of use-wear traces on the endscrapers across macro-units A and D. One hundred forty-seven of the examined tools display traces on their identified functional edge (Fig. 5: RF 31, 55, 2, 157), 49 did not show any trace, while only nine were recorded as uncertain given either poor or confusing traces. It is reasonable to assume that some of the tools that show no evidence of use may have been completely resharpened or used too briefly. Used endscrapers were divided into two main groups: those that were clearly used on hide-with traces evident under low and high magnification-and those with poorly developed traces or traces preserved in small spots only-visible under high magnification-and probably resulting from hide working. 


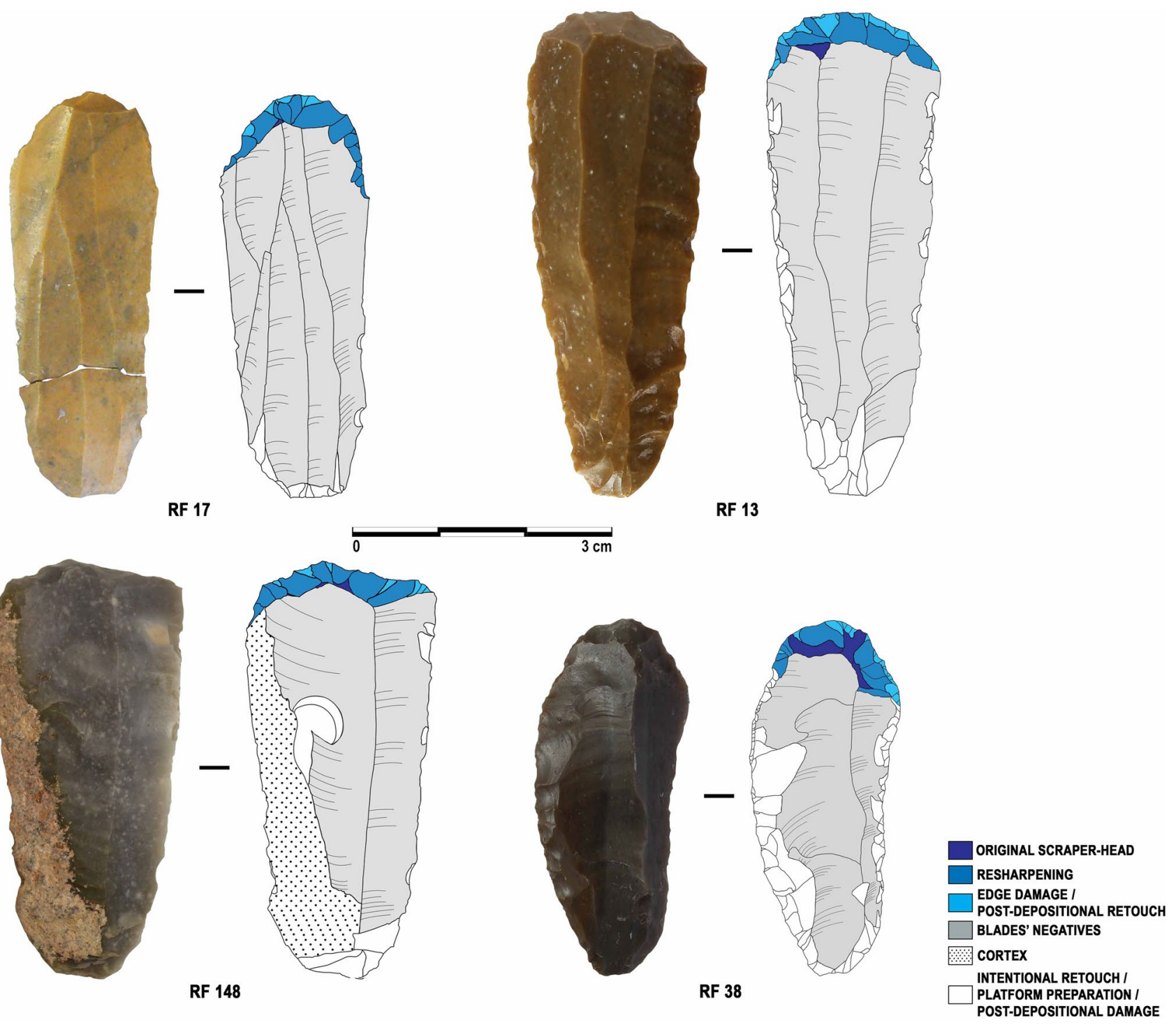

Fig. 4 Example of endscrapers and sketches showing different degrees of resharpening of the functional extremity. Remnants of the original scraper-heads are in dark blue, while resharpening retouch

\section{Layers A1-A2}

Seventy-four percent $(n=102)$ of the 138 endscrapers examined show clear traces of use. The 74 endscrapers used in the processing of hide show clear and well-developed traces of use. Rounding, a typical feature of hide use-wear, was recorded on all the tools and it is, generally, partially cut by resharpening without entirely removing the use-wear traces so that these remained recognizable (Fig. 5: RF 31, 2). At least 16 endscrapers display use-polish in association with rounding (Fig. 5: RF 157). The polish distribution is continuous and follows every protrusion or indentation of the edge. On six endscrapers, the polish appears slightly brighter and associated with a gentle/moderate edge rounding. These and post-depositional edge damages are lighter. Intentional retouch, post-depositional damages and scars on the proximal extremities due to platform preparation are in white. Photos and drawings: A. Aleo

traces seem associated with fresh or moistened hide working (cf. Keeley 1980; Loebel 2013). On eight endscrapers, striations, perpendicular to the edge, are also associated with use-polish and rounding. On another 28 endscrapers, intense resharpening partially removed the traces of use. The traces are visible only on the prominent points between resharpening negatives. Despite this, preserved spots of well-developed rounding permitted us to attribute these traces to hide working as well. On five endscrapers, use-polish is also associated with rounding. Striations perpendicular to the edge, indicative of the use motion, were documented on two tools.

Only one endscraper appeared to provide evidence for contact with hard materials, but the localized polish proved to be a result of contact with the bone hammer during 
Fig. 5 Selection of manufacturing and use-wear traces documented on the endscrapers from Fumane (RF) macro-units A and D. Endscraper 18: left, retouch striation (indicated by the arrow) on the ventral distal scraper-head due to impact with the bone retoucher $(\times 200)$; right, retouch striation (indicated by the arrow) associated with edge damage on the ventral distal scraper-head probably from impact with a bone retoucher $(\times 200)$; endscraper 31: well-developed rounding cut by resharpening on the ventral distal scraper-head $(\times 200)$; endscraper 55: edge damage, edge rounding and striations on the ventral distal left scraperhead $(\times 200)$; endscraper 2: edge rounding interrupted by resharpening on the ventral proximal scraper-head displaying non-detached resharpening flake $(\times 200)$; endscraper 157 : edge rounding and bone polish from the contact with the hammer on the ventral distal scraper-head showing incipient crack from unsuccessful resharpening attempt $(\times 200)$. Micrographs: A. Aleo, V. Rots, N. Taipale
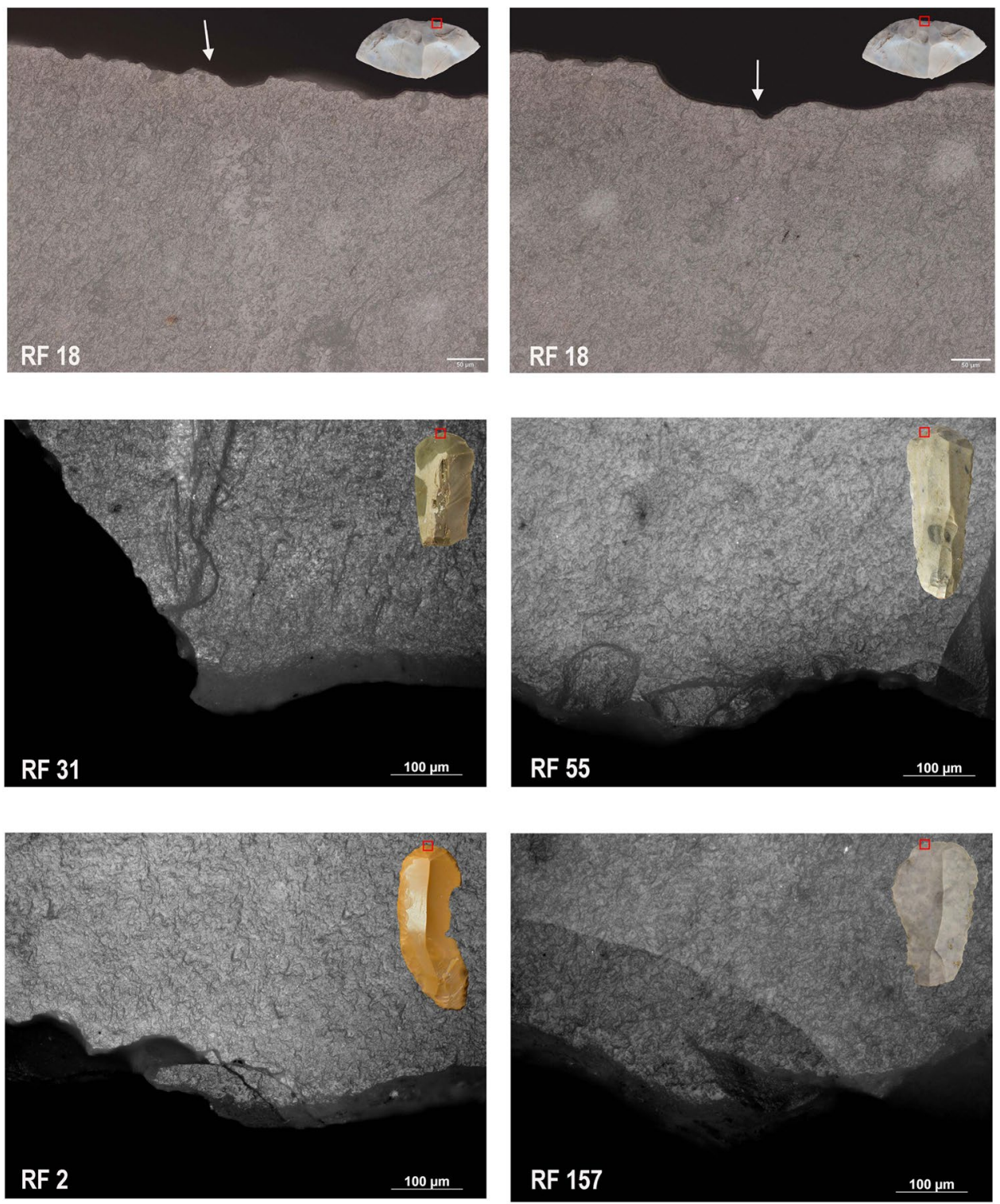

resharpening. This contact generally leads to the formation of striations, but it may also occasionally lead to specific polish spots. Striations are associated with the concavity of the negative scar of the resharpening flake, while limited spots of polish are located only in the adjacent areas (cf. Rots 2010a, b) (Fig. 6a, b, c). Due to their pattern of distribution on the tool and the absence of any additional distinctive evidence, we have ruled out that these traces resulted from bone working. The occurrence of about one hundred bone retouchers in the assemblage (Jéquier et al. 2018) is an additional supporting evidence for this. Besides, the scraper-head has numerous indications of intense resharpening, with spots of use-wear polish on hide preserved only near the lateral edges (Fig. 6a). In the more central zone of the scraper-head, remnants of the hide use-wear are visible but without the area showing the impact on the edge, as may be expected on resharpened edges (Fig. 6d). For eight endscrapers, traces are unclear or insufficiently developed and cannot be interpreted with confidence.

The functional edge is located either on the distal or on the proximal extremity of the blank, with a high percentage of the former (66\%). Endscrapers with interpretable wear traces were used almost exclusively in the different stages of hide working with transversal movement. Two tools show traces on the lateral edges, probably related to different actions, as for, e.g., cutting or scraping soft materials like hide.

\section{Layers of macro-unit D}

Among the 67 endscrapers examined, 44 (66\%) show traces of use localized on the scraper-head. Thirty-two endscrapers 
Table 7 Distribution of use-wear traces on the analyzed Protoaurignacian endscrapers of Fumane. The "used" group comprises: tools with clear traces from hide working and tools with traces probably resulting from the contact with hide. The "no use-wear traces" group consists of tools completely resharpened, tools affected by intense post-depositional surface modifications (PDSM), and tools with no evidence of use at all. Endscrapers affected by intense post-depositional alterations were analyzed only under low magnification

\begin{tabular}{lllll}
\hline & $\mathrm{A}$ & $\%$ & $\mathrm{D}$ & $\%$ \\
\hline Used & $\mathbf{1 0 2}$ & $\mathbf{7 3 . 9}$ & $\mathbf{4 4}$ & $\mathbf{6 5 . 7}$ \\
Hide working & 74 & & 32 & \\
Probable on hide & 28 & & 12 & \\
Bone working & 0 & & 0 & \\
Uncertain & $\mathbf{8}$ & $\mathbf{5 . 8}$ & $\mathbf{2}$ & $\mathbf{3}$ \\
No use-wear traces & $\mathbf{2 8}$ & $\mathbf{2 0 . 3}$ & $\mathbf{2 1}$ & $\mathbf{3 1 . 3}$ \\
Totally resharpened & 5 & & 2 & \\
Intense PDSM & 9 & & 7 & \\
Unused & 14 & & 12 & \\
Total & $\mathbf{1 3 8}$ & $\mathbf{1 0 0 . 0}$ & $\mathbf{6 7}$ & $\mathbf{1 0 0 . 0}$ \\
\hline
\end{tabular}

were used for scraping hide and starkly display well-developed traces of use. The use-wear polish, documented in five tools, is associated with explicit rounding and, in one case, also with striations indicative of the use motion. Based on the characteristic of the polish, one tool may have been used for working fresh or moistened hide. On 12 endscrapers, the use-wear traces are poorly developed, given that these were partially removed by resharpening. However, isolated spots of developed rounding in between resharpening scars allow us to attribute these traces also to hide working even though they are less well-developed. In two cases, striations, perpendicular to the edge, are also associated with edge rounding. We cannot interpret with confidence the traces on two endscrapers, because they are insufficiently developed. None of the endscrapers provided explicit evidence of use in bone or wood working.

The functional edge is almost exclusively located on the distal extremity of the blank (83\%). Only four tools (9\%) have their scraper-head manufactured on the proximal extremity. All tools with interpretable traces of wear were used in scraping hides with a transverse motion.

\section{Fragmented scrapers with intact scraper-heads}

Our sample of 205 specimens also includes 20 broken endscrapers with only the functional extremity preserved. We excluded these fragments from the metric analysis, but they were examined microscopically to understand the cause of the fracture. Eighteen fragments show evidence of use related to hide working, and they are already comprised in the aforementioned number of used pieces $(n=147)$. All fragments share similar dimensions and have fractures that are systematically initiated in bending, very close to the retouched edge (see Fig. 7). It is, thus, likely that these fractures were accidents that occurred during resharpening. In most of the cases, we could confirm this on the basis of microscopic analysis, as the resharpened areas did not show any sign of use, either within the concavity of the negatives or on the prominent points as would be the case if the fracture had occurred in (subsequent) use. Besides, we documented secondary damage in association with the fracture, in some cases in combination with bright spots or other friction wear, which indicates that these fractures likely occurred at the haft limit (Fig. 7a, b) (Rots 2005, 2010a). Experimental evidence has indicated that fractures occurring at the haft limit are generally initiated in bending and show an important amount of secondary damage around the initiation and termination, as well as on the edges (Rots 2010a). This secondary damage is the result of counter-pressure against the haft (Rots 2010a) and often leads to intense localized friction leading to bright spot formation (Rots 2002b). Two endscrapers show a complex fracture that only occurs when a tool is submitted to a high stress, like in the case of high-pressure motions. In both cases, frictional spots on the fracture surface are associated with damage (Fig. 7b). In one case, poorly developed traces of use-wear are visible on the resharpened edge. All this evidence combined seems to indicate that the fractures on these two fragments likely occurred during hafted use (cf. Rots 2010a).

\section{Tools, cores, or both?}

Carinated technology is common in all studied Protoaurignacian assemblages at Fumane Cave. We identified several carinated endscrapers in the macro-units $\mathrm{A}$ and $\mathrm{D}$. In the latter, their frequency slightly increases (Falcucci et al. 2020). In a previous technological study, Falcucci and Peresani (2018) proposed the classification of carinated endscrapers at Fumane as bladelet cores, confirming data produced at several other sites (e.g., Dinnis 2008; Domingo et al. 2012; Hays and Lucas 2000; Le Brun-Ricalens 2005, Schulte im Walde 1987). A lithic refit supports this interpretation. They are distinguishable from the rest of the bladelet cores because the frontal regression of the flaking penetrates orthogonally along the longitudinal axis of the blank. Carinated endscrapers are usually made from thick blanks and the steep striking platform is always located above the ventral face (Fig. 8). The knapping pattern is strictly unidirectional, and its progression is semi-circumferential. In most cases, the reduction pattern is convergent. Common maintenance operations consist of the isolation of the flaking surface by knapping broad, plunging flakes. These flakes are removed at the intersection with the core flanks and are transversal to the main production axis. These operations are conducted at different phases throughout the reduction 


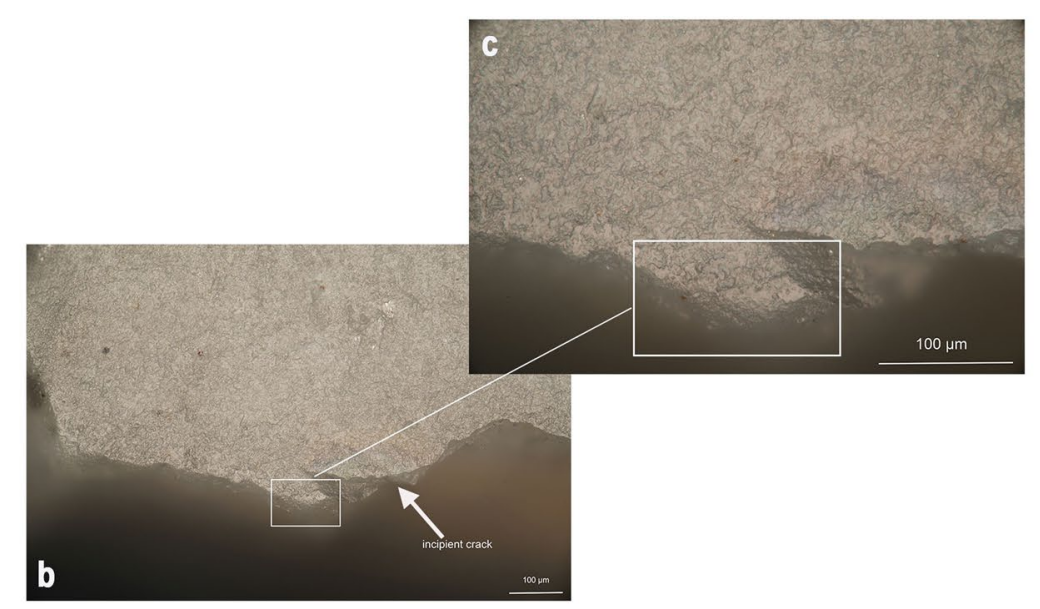

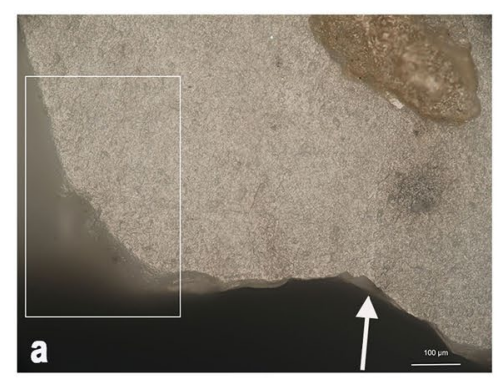

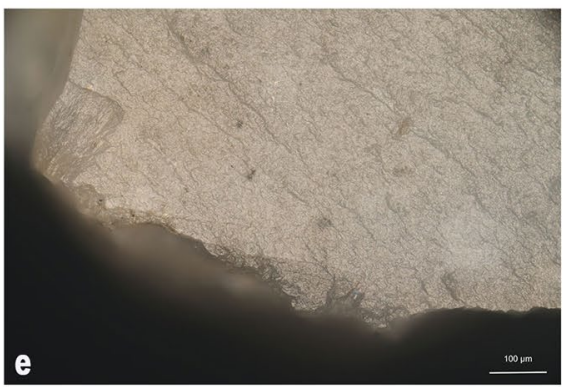

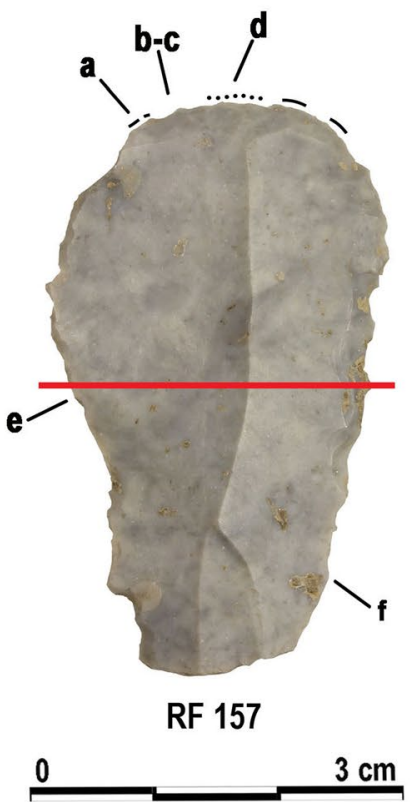
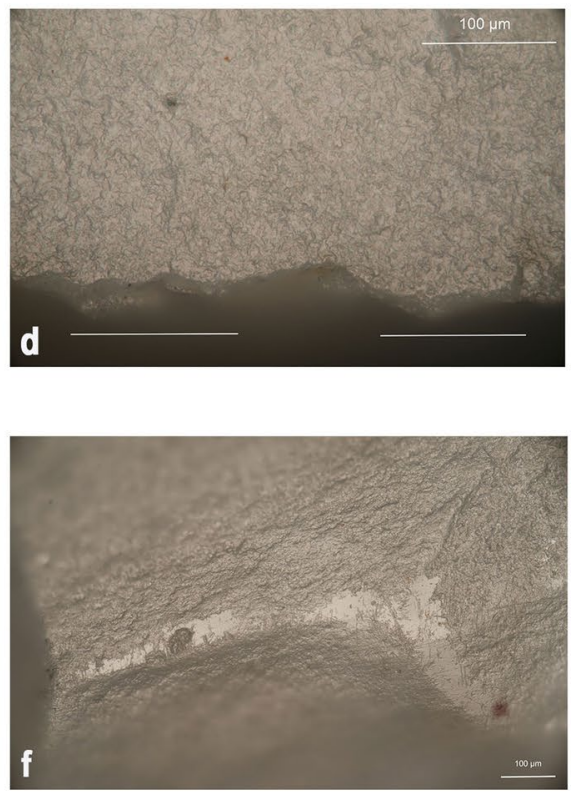

Fig. 6 Use-wear and hafting trace distribution on endscraper 157 (black dotted line: poorly developed traces; black solid line: welldeveloped traces; red solid line: haft limit. (a) Preserved hide usewear (rectangle) interrupted by resharpening removal showing striation from contact with the bone hammer (arrow) $(\times 200)$; (b) incipient crack due to unsuccessful resharpening blow (arrow) and spot of well-developed bone polish (rectangle) on the ventral scraper-head

sequence and give some specimens a characteristic nosed morphology. This procedure is similar to the reduction procedure described for semi-circumferential bladelet cores, supporting the classification of these artifacts as bladelet cores (Falcucci and Peresani 2018). The goal of the production is to produce bladelets with curved profiles, whereas twisted blanks are rare (Falcucci et al. 2017). Overall, bladelets are shorter if compared to those produced from bladelet cores oriented according to the longitudinal axis of the blank. These differences might be strictly related to the need
( $\times 200)$; (c) detail of (b), as indicated $(\times 500)$; (d) remains of hide use-wear polish on the ventral scraper-head, the impact on the edge has been removed by resharpening $(\times 500)$; (e) cracks and damage from friction in the haft around the haft limit on the ventral medial left edge $(\times 200)$; (f) intense friction wear including hafting bright spots from friction within the haft on the ventral proximal right edge $(\times 200)$. Photos and micrographs: V. Rots, A. Aleo

of Protoaurignacian knappers to obtain blanks with variable morphometric features (Falcucci et al. 2018).

The eight examined cores/scrapers, made on thick flakes, display a regular convex edge shaped by the removal of small blades. Some also exhibit two lateral notches or removals that control the transverse convexity of the removal surface. No traces of use have been noticed. The only traces that are visible are incipient cracks, microflaking, knapping polish, and striations, all of which are a consequence of contact with the hammer during knapping or platform preparation. The 


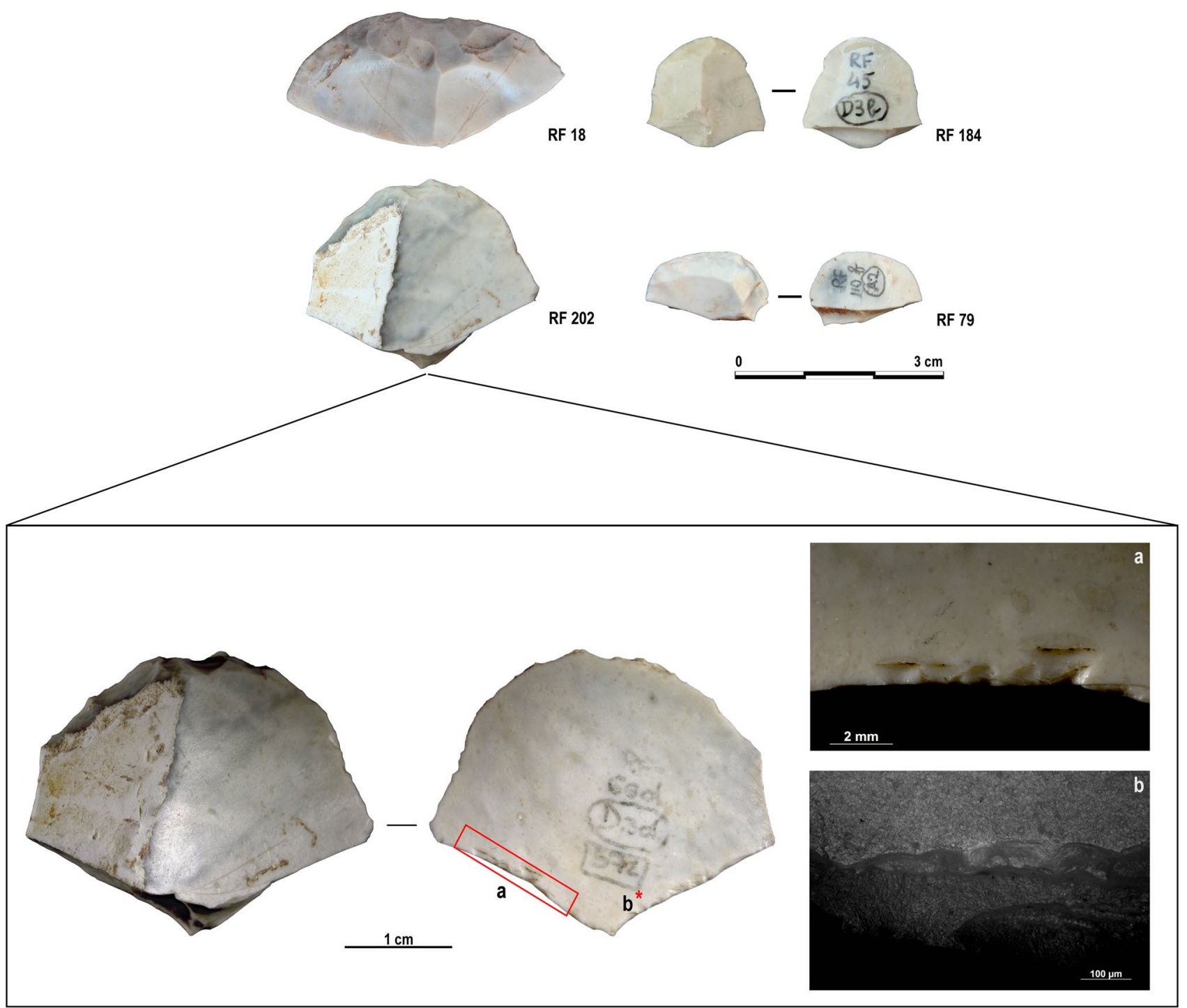

Fig. 7 Sample of four fragmented endscrapers with intact scraperhead accidentally fractured during resharpening and use, from Fumane (RF) macro-units A and D. In focus: dorsal and ventral view of the endscraper 202 showing (a) edge damage on the ventral right

functional analysis thus confirms that these carinated endscrapers were not used as tools, but primarily served as cores for bladelets. There are also no indications that the carinated scrapers would have been used as tools between different knapping sessions. While bladelet production would obviously have removed potential use-wear, it remains a fact that none of the carinated endscrapers were discarded in a state that suggests any (intermediate) use.

\section{Hafting}

Following Rots' (2002a, 2003, 2010a) methodology, we also examined whether the endscrapers showed any evidence of point of the fracture $(\times 20)$; (b) friction spot associated with edge damage on the fracture $(\times 200)$. The use-wear indicates that the fracture likely occurred while hafted and at the haft limit. Photos: A. Aleo, N. Taipale

hafting. Indeed, we did find evidence of hafting, but the type of evidence varied, leading to varying degrees of certainty. We examined 205 endscrapers in total for use-wear: 146 show evidence of use on hide, at least nine show reliable evidence of hafting (Fig. 9), at least 10 show probable evidence of hafting, and at least 31 show possible evidence of hafting. The high number of broken endscraper extremities further suggests that hafting occurred regularly, as resharpening of hand-held scrapers does not lead to the types of fractures observed (cf. Rots 2010a) (see Sect. 3.4).

Subsequently, we selected 11 endscrapers with potential hafting evidence to examine whether indications for a particular hafting arrangement could be identified based on the 
Fig. 8 Example of carinated endscrapers and their schematic drawings from Fumane (RF) layer D3b (194) and layer A2 (140). Arrows show the direction of bladelet removals, here numbered in ascending order accordingly to their chronological succession. The oldest reduction phases turn darker, while the successive phases turn lighter. Photos and drawings: A. Falcucci
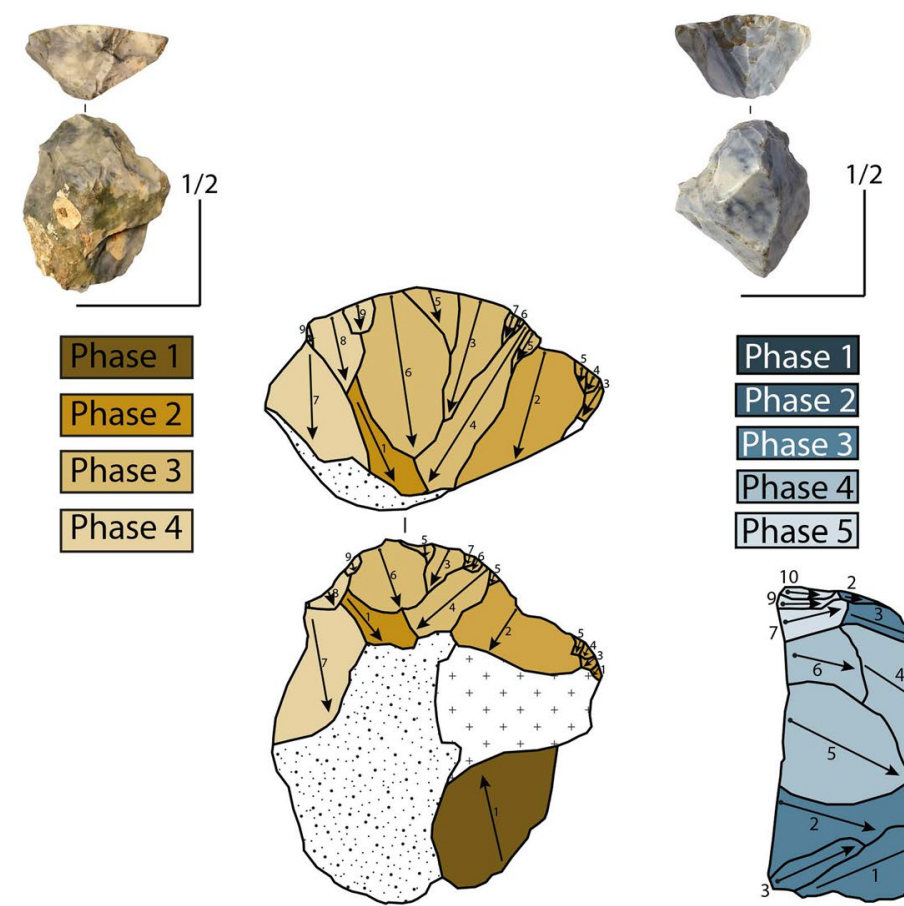

RF 194
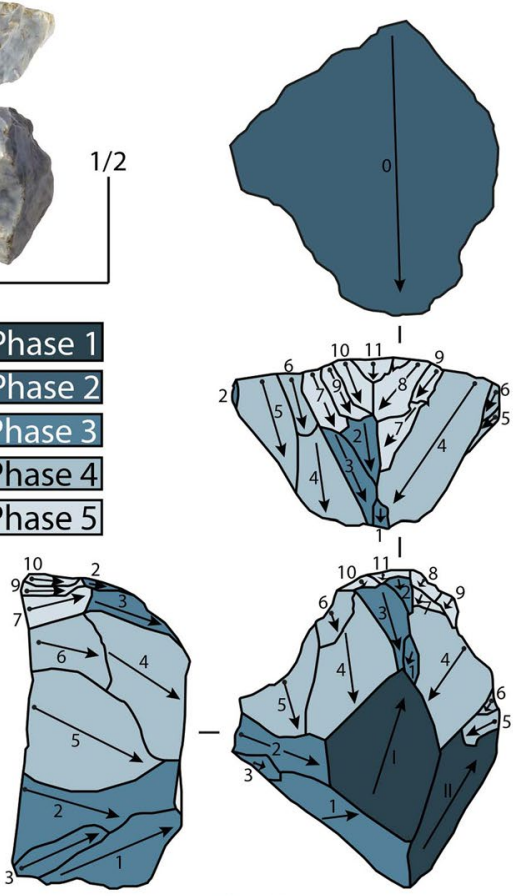

RF 140

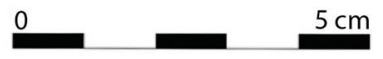

wear traces. The selection of these tools attempted to cover the range of morphological variation and variation in usewear evidence in the assemblage. These pieces were examined in detail under low and high magnification.

We cannot easily identify the way in which these endscrapers were exactly hafted (cf. Rots et al. 2006), but several features provide clues that can help in this respect. First, intense edge damage is initiated within the handle, which is indicated by its association with bright spots (cf. Rots 2002b) and striations, whose formation necessitates intense localized friction (Fig. 9c, d, e). Secondly, several pieces have a fracture on the proximal extremity that occurred within the handle, as demonstrated by the fracture characteristics in combination with the associated damage and flint-on-flint friction wear. In addition, on some lateral edges, contact with hide has also been noted. It, therefore, seems most likely that a juxtaposed and partially slotted handle was used, with the proximal extremity being secured in the slot and the remainder of the hafted part of the blank being secured against the handle with bindings. This hafting method permitted some movement to occur within the haft, which explains the hafting polish present in zones close to the lateral edges, on the bulb and on the ridges. The material of the handle is difficult to determine. In some areas, polish reminiscent of a bone handle was observed, but the possibility of a wooden handle cannot be entirely excluded due to similarities between dry/seasoned wood polish and bone polish (cf. Vaughan 1985). Given that wood is used for handles when it is dry, the polish characteristics overlap to some extent with bone (cf. Rots 2010a).

\section{Tool life cycles, morphology of scraper-head, and tool use}

The detailed analyses of the endscrapers provide information about scraper-head morphologies and their use-life, including use, resharpening, and reasons for discard. In general, endscrapers are subjected to repeated resharpening sessions during their use-life (Blades 2003). A gradual decrease in size and change in shape of the distal part are some of the visible modifications caused by the physical action of resharpening stone tools, like also in the case of endscrapers (Morales and Vergès 2014, p. 303). However, minimal morphological variations accumulated after each sharpening event could result in a slightly different scraperhead morphology compared to the initial one (Collin and Jardon-Giner 1993). On a morphological level, we classified all analyzed scraper-heads into three main groups (see Fig. 10). The first group consists of endscrapers $(n=76)$ shaped with regular convex scraper-heads (Fig. 10: RF 71, $2)$. In the second group, endscrapers $(n=47)$ have oblique scraper-heads (Fig. 10: RF 13, 17). It is unclear whether this shape is intentional or results from uneven resharpening. This shape may have been designed to address specific tasks in different phases of hide working or to fit a particular hafting arrangement. Further detailed microscopic analyses 

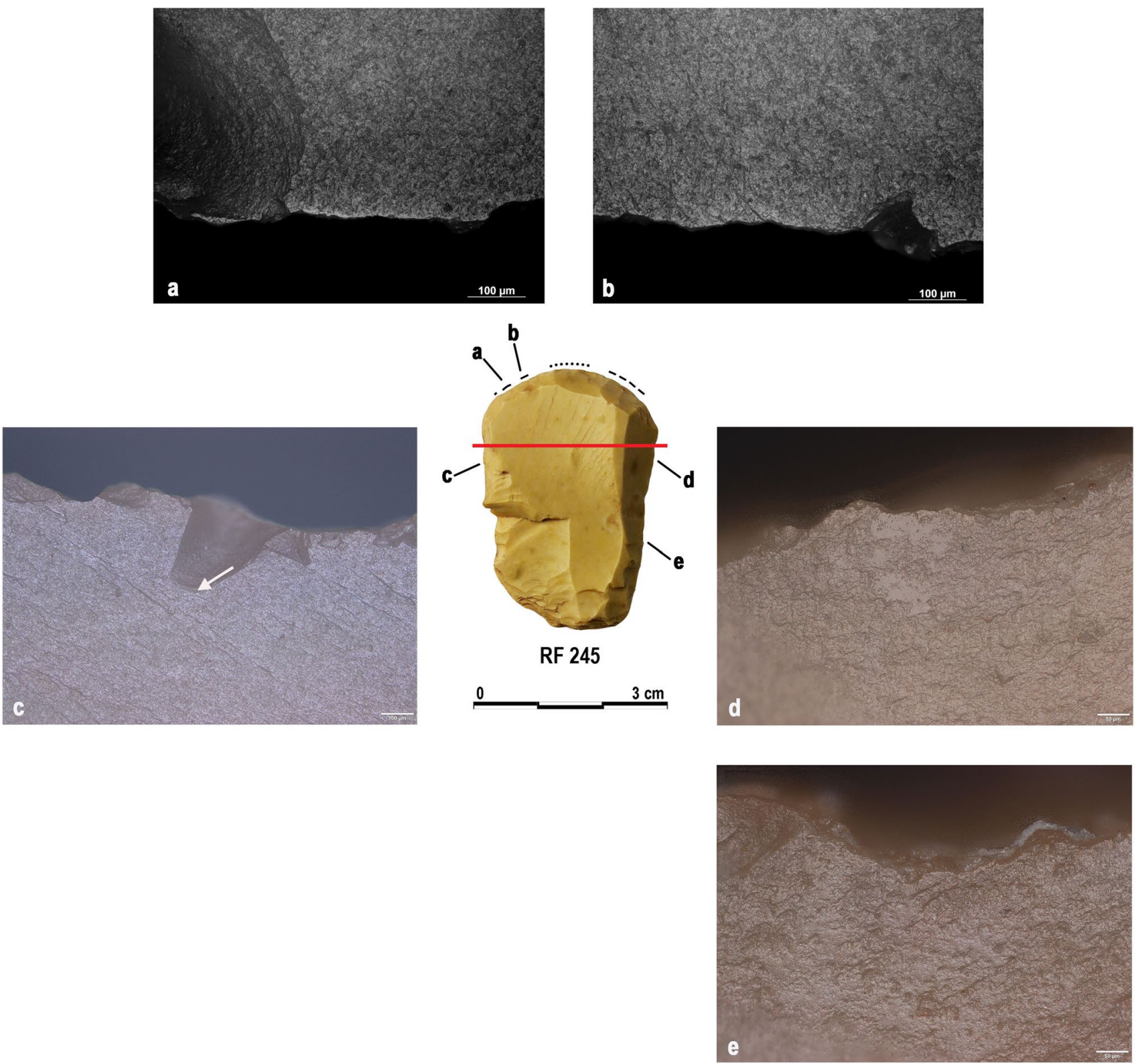

Fig. 9 Use-wear and hafting trace distribution patterns on endscraper 245 used for hide working (black dotted line: poorly developed traces; black solid line: well-developed traces; red solid line: haft limit). (a) Use-wear polish on the ventral distal left scraper-head $(\times 200)$; (b) use-wear polish and striations on the ventral distal left scraper-head;

might clarify this point. In the third group, scraper-heads $(n=44)$ are irregular (Fig. 10: RF 278, 54). Microscopic analysis proves that this shape is not intentional, but that it is a consequence of intense and repeated resharpening. A small sample of endscrapers $(n=10)$ display a straight working edge. This morphology also seems to be a direct consequence of resharpening but resharpening that occurred when close to the haft limit. Previous studies (e.g., Jardon-Giner and Sacchi 1994; Rots 2005) demonstrated that the shape of (c) hafting striation (arrow) associated with edge damage on the ventral mesial left edge $(\times 100)$; (d) hafting bright spots associated with edge damage on the ventral mesial right edge $(\times 200)$; (e) friction haft polish on the ventral proximal right edge $(\times 200)$. Photos and micrographs: A. Aleo, V. Rots, N. Taipale

the scraper-head after resharpening can be influenced by the proximity to the haft. The proximity of the haft end inhibits the creation of a convex scraper-head, so the last series of resharpening may result in a straighter working edge (Morrow 1997).

By looking at the distribution of use-wear along the worked edge, we were able to identify two different resharpening strategies because of the existence of partial or incomplete resharpened scraper-heads. In the first 
Fig. 10 Ventral view of a sample of endscrapers from Fumane (RF) macro-units A and $\mathrm{D}$ showing the most distinctive scraper-head morphologies subjected to modification after use, resharpening or incomplete resharpening. $(71,2)$ regular convex $(\times 8),(13,17)$ slightly oblique $(\times 10),(278)$ irregularpointed $(\times 10),(54)$ irregular $(\times 5.6)$. Photos: A. Aleo, N. Taipale
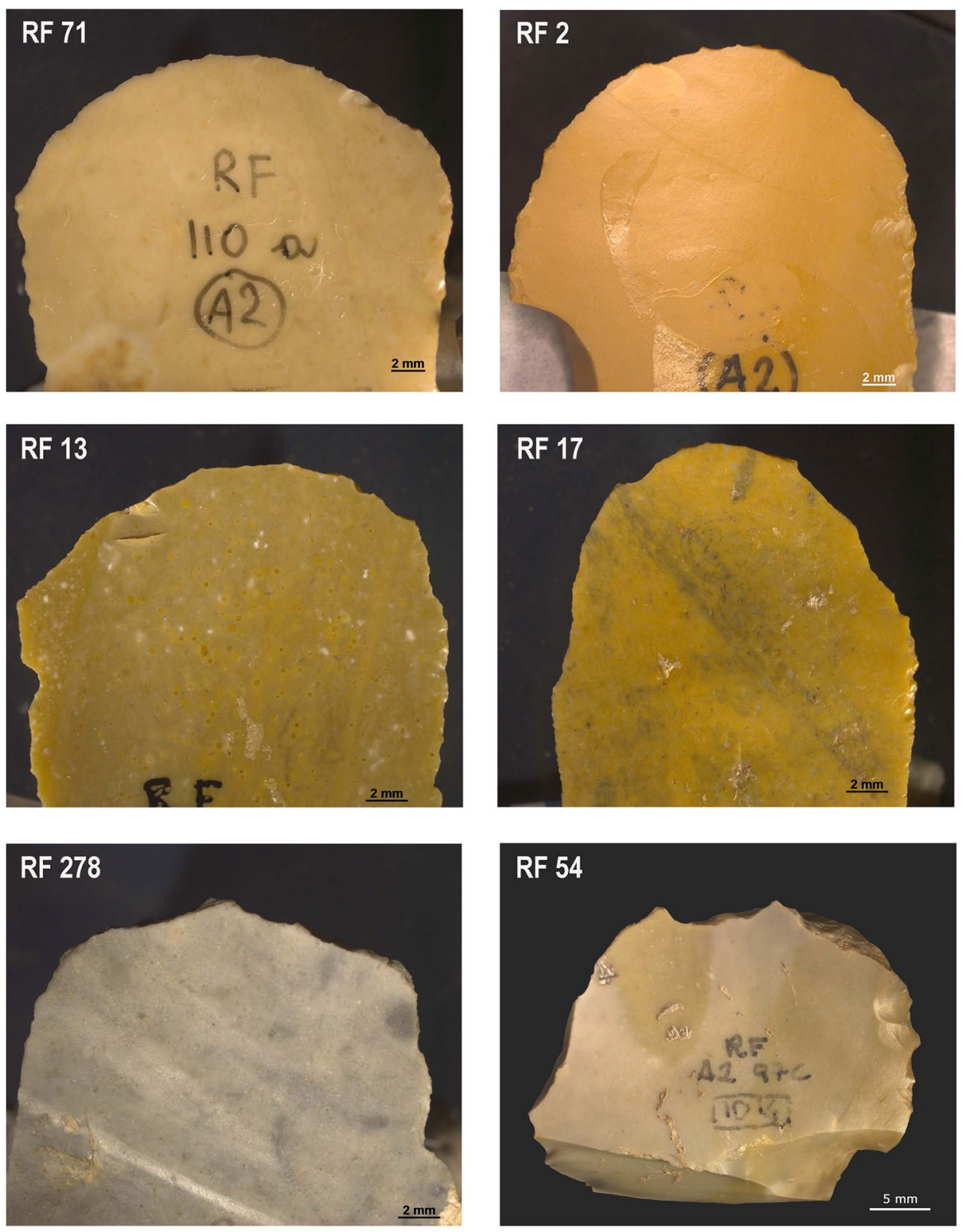

strategy, resharpening started from both tool edges towards the center of the scraper-head. This resulted sometimes in an irregular-pointed scraper-head morphology with evidence of use preserved almost exclusively on a protrusion located around the middle of the working edge. We detected this particular shape on 11 endscrapers. In the second one, resharpening started from one lateral edge of the tool to continue gradually towards the other lateral edge. Incompletely resharpened endscrapers found in that group are characterized by a more or less marked change in the curvature of the scraper-head. The best developed use-wear traces are preserved in the unsharpened part at the extremity of the scraper-head towards one of the lateral edges.
At least two endscrapers provide features that might indicate the presence of beginner flintknappers (cf. Rots 2005). We distinctly observed differences in resharpening skill on endscraper 223 (Fig. 11). The scraper-head is dismantled by an intense, clumsy, and irregular resharpening, with the distal margin affected by multiple overlapping step/ hinged fractures (Fig. 11b). While well-developed use-wear traces are preserved only on a small area on the left side of the original scraper-head (Fig. 11e), incipient cracks and undetached resharpening chunks are widespread all over the working edge (Fig. 11b, c). The well-developed edge rounding on the left is connected to a use cycle preceding the resharpening. The dorsal ridge of the tool exhibits scarring probably due to resharpening on an anvil (Fig. 11a). The 

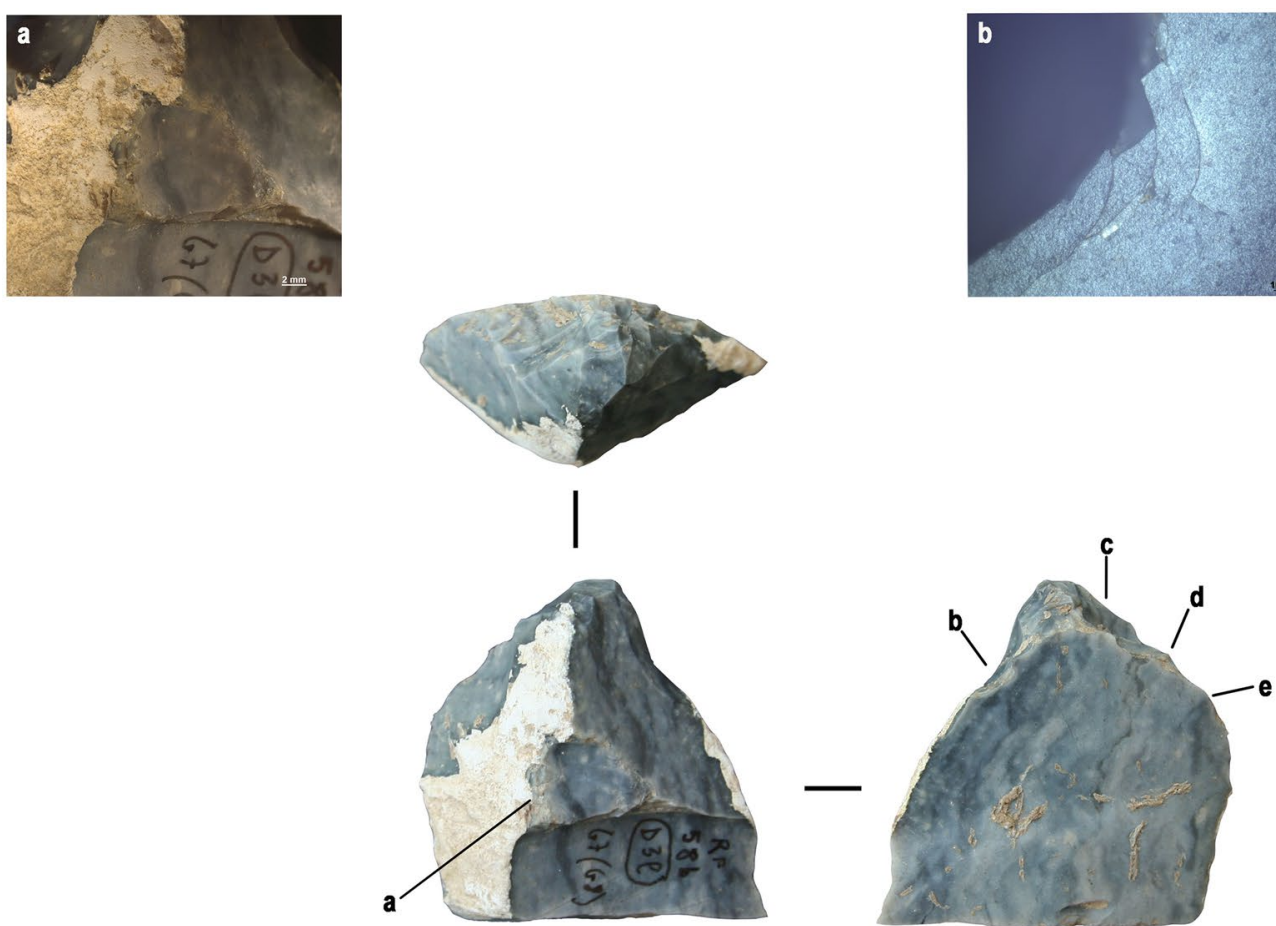

RF 223

Fig. 11 Layer D31, the endscraper 223 shows the effects of ineffective resharpening. (a) Damage on the dorsal ridge probably due to resharpening on anvil $(\times 8)$; (b) incipient cracks from resharpening on the ventral distal scraper-head $(\times 100)$; (c) overlapping resharpening

intense resharpening resulted in a proximal fracture. The endscraper was likely discarded because of the morphology of the distal edge and because the angle of the scraper-head did not allow for further resharpening.

Endscrapers were discarded after several episodes of use. The majority of the studied endscrapers display evidence of resharpening attempts before final discard (cf. Loebel 2013). Edge damage, superimposed step fractures, protrusions, and incompletely resharpened edge sections all resulted from these failed resharpening efforts. Tools were also discarded when the scraper-head angle became too obtuse to perform subsequent edge resharpening or because of a fracture. We found evidence that the endscrapers were resharpened while still secured in their haft, as is also demonstrated by the frequent fractures at the haft limit. and micrographs: A. Aleo, N. Taipale

\section{Discussion}
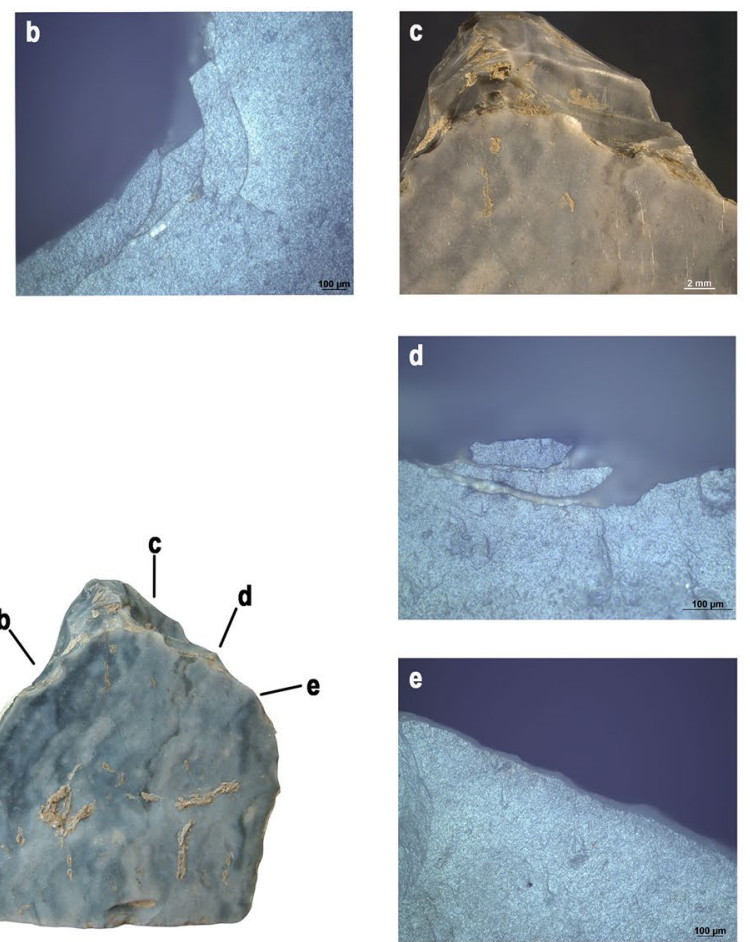

scars with hinged termination $(\times 10)$; (d) non-detached resharpening flakes on the ventral distal scraper-head $(\times 200)$; (e) edge rounding from use on the ventral left side of the scraper-head $(\times 100)$. Photos

\section{The design and maintenance of endscrapers at Fumane within the Protoaurignacian and Aurignacian cultural framework}

Endscrapers in the Protoaurignacian and Aurignacian are characterized by a substantial morphometric variability which makes it difficult to define a prototype. Reports from a large group of sites illustrate the morphometric profiles of these tools in relation to the technological provenance of the original blanks with the intention to shed light on the criteria driving their selection. For instance, according to A. Palma di Cesnola (2004), long endscrapers made on blades are not present in the Protoaurignacian layer 24BII at Paglicci Cave in southern Italy. A majority of these tools have nosed and ogive type fronts, with extensive retouch along the sides, even on the very few carinated types. Far west in France, the early Aurignacian endscrapers from Tuto de Camalhot (40ky BP-Ariège) were mostly made on blades, with retouched sides on one-fourth of the total number of these tools (Bon 2002). Shortening due to resharpening affected $70 \%$ of this category, which does not include those specimens that are $5 \mathrm{~cm}$ in length with thickness values ranging $0.4-0.6 \mathrm{~cm}$ to 
$1.2 \mathrm{~cm}$. A small group of endscrapers was made on flakes selected opportunistically but with attention to their thickness. These endscrapers on flakes are thicker than endscrapers on blades (Bon 2002). The Aurignacian endscrapers of Grotte des Hyènes à Brassempouy (Landes) come in various forms, including double front, circular, ogive-like, nosed, and carinated tools (Bachellerie et al. 2011). The blanks selected for production of the endscrapers are blades with unretouched or unequally retouched sides - and flakes (in a higher percentage), although other flaked products were used. Flakes look thicker than blades and were also modified in nosed endscrapers. These endscrapers were manufactured on primary flake products and on by-products of blade-making and were interpreted as proper tools (Bon 2002). Régismont-le-Haut, one of the oldest Aurignacian sites in Mediterranean Languedoc, is also characterized by high variability in endscrapers' shapes and forms (Anderson et al. 2018; Bon 2002). Here, flakes and laminar flakes are used more often than blades. The latter were modified by leaving the sides unretouched or unequally retouched. Lengths are generally short, with most of the pieces less than or equal to $5 \mathrm{~cm}$. Carinated pieces are also made on cortical flakes. At Grotte de L'Observatoire, among the seven endscrapers recovered in layers $\mathrm{G}$ and $\mathrm{F}$, one is carinated, while the others are made on thick blades, only a few of which are retouched (Porraz et al. 2010).

From this brief review, it appears that the production of endscrapers mainly varied according to the raw blank selected for their manufacture, as is also the case at Fumane. This assemblage contains both intact and fractured regular blades and a variety of by-products issued from the whole laminar reduction sequence. Variation in thickness is a consequence of the presence of by-products, which are thicker than blanks coming from the optimal production phase. This morpho-metrical variability is also increased by the fact that complete endscrapers were discarded at different stages of use. Repeated resharpening sessions lead to a reduction in tool length and may result in breaking the blank. However, the endscrapers show some recurring attributes. The Fumane assemblage is dominated by endscrapers made on regular blanks with limited thickness, slightly convex profiles, axial and distal active edges, and convex scraper-heads, mostly characterized by intense resharpening. Typologically, single frontal endscrapers are the most common endscrapers in the assemblage, carinated and nosed forms are less numerous. Lateral retouch occurs on only a few specimens.

Furthermore, the endscrapers from the two Protoaurignacian complexes at Fumane do not provide evidence for any type of diachronic trend expressed through a change in the tool features at every morphometric and functional level. In contrast to the Fumane evidence, new tool morphologies are recorded in other regions during later chronological phases. This is the case in the Aquitaine basin, France, where Caminade-type endscrapers appear in a group of sites (Anderson et al. 2016; de Sonneville-Bordes and Mortureux 1955). The Caminade endscraper is a short flake converted into a modulated tool composed by a front adjacent to finely retouched sides. However, unlike the other endscrapers, the purpose here was to make insets to be hafted into composite tools, with the final goal to carry out fine butchering activities (Anderson et al. 2016).

Maintenance: resharpening The endscrapers were resharpened frequently during their life. Tools were used, maintained, and used again. Different sessions of resharpening were detected on a high number of scrapers from both units at Fumane. In multiple cases, we were able to determine that the resharpening was performed with a bone hammer, as indicated by the morphology of the striations and the impact features (Rots 2010b) and the presence of bone retouchers in the assemblage (Jéquier et al. 2018). Resharpening was also observed on 19 tools lacking evidence of use. It is reasonable to suppose that these tools may have been used and then extensively resharpened.

Our study shows that endscrapers were used and continuously resharpened until they became exhausted and discarded. Despite the abundance of high-quality raw materials in the site's surroundings, a high number of endscrapers were abandoned in a late stage of reduction. One explanation for the abundance of resharpened tools might have been the fact that most of them were likely hafted, as demonstrated by macroscopic and microscopic observations. Hafted tools require more technological investment in terms of their manufacture. Therefore, they were curated and maintained for as long as possible.

Functionality The macroscopic and microscopic investigations of the use traces on the Fumane endscrapers shed light on the activities that were carried out in the cave, which used a large number of tools ( $71 \%$ of the sample) to process hides using transverse motion. In most cases, only one edge, the distal end, was used. We systematically detected the distinctive features of hide working (edge rounding, polish with rough texture and dull appearance, rare striations) on the scraper-heads. Even though several tools display only poorly developed use-wear traces (see the Results section), their association and combination, their distribution pattern along the edge, and the extremely high consistency of use-wear across the whole studied sample allowed us to interpret them as hide working related. Although the traces resulting from processing hides exhibit specific traits that are fairly easy to recognize (see Keeley 1980; Vaughan 1985), the exact state of the hide is more difficult to determine. As briefly pointed out in the Results section, slightly brighter polish and light edge rounding were observed on ten well-preserved pieces and interpreted as resulting from working fresh or moistened 
hides. According to Keeley (1980), dry hide polish is generally dull, rough, and pitted while fresh hide polish is usually greasier and brighter (cf. Loebel 2013). There seems to also be a correlation between the degree of edge rounding and the dryness of the hide (Rots 2005). Working dry hide normally consists of a heavier rounding of the functional edge (Collin and Jardon-Giner 1993; Keeley 1980). This difference in fresh versus dry hide traces is well documented in the experimental hide working tools in the reference collection we used for this study.

The presence of such a specialized group of tools for working animal soft tissues may reflect an increased need for hides, as highlighted by the number of carnivores exploited during the Uluzzian and Protoaurignacian occupation of the cave (Tagliacozzo et al. 2013; Malerba and Giacobini 1995). The occurrence of butchering marks on wolf, fox, bear, and lynx bones, which point to skinning, suggests that these species were primarily hunted for skins and furs rather than for food (Romandini et al. 2020; Tagliacozzo et al. 2013).

None of the tools showed clear sign of a use on bone, emphasizing the role of the endscrapers as highly specialized tools for working hide. The Protoaurignacian layers have produced a varied industry of bone and antler comprising five spear points in the late Protoaurignacian layers (four on antler and one on bone) and one antler point recovered at the interface between units A1 and D3. Four of these are split-based points. While bone tools usually require little modification, Aurignacian points are intensively worked to produce a functional projectile point through a complete modification of the original blank (Tejero 2014; Tejero and Grimaldi 2015). Fine, long longitudinal striations, parallel to each other, were systematically observed on the surfaces of the bone and antler artifacts from Fumane. These traces were likely produced using a lithic tool using transverse motion with a working edge that is oriented perpendicular to the longitudinal axis of the point (Bertola et al. 2013). Although endscrapers seem to be the most suitable tools for this activity, our study demonstrates that they were not involved in the manufacture of bone points during the late Protoaurignacian use of the cave. A use-wear study that also integrates classes of lithic tools other than endscrapers and pebbles (Caricola et al. 2018) may help to clarify whether other tool types were used to produce, finish, or maintain these objects. However, we also cannot exclude that bone points were imported into the site as finished products.

Toolkit specialization is a proxy generally used to point out technological and behavioral modernity. The proliferation of tool types during the Upper Paleolithic is often seen as a direct reflection of a specific tool versus function correlation (Mellars 2004; Roebroeks 2008; Villa and Roebroeks 2014). Unfortunately, only a few EUP assemblages have been functionally examined and these arguments have not been methodologically tested. The endscraper assemblage from Fumane is characterized by a high functional consistency and specialization. The results of our macro- and micro-wear study support the argument that endscrapers at Fumane primarily functioned as hide working tools. In contrast, the results of residue and use-wear analyses of Aurignacian artifacts, including endscrapers from Hohle Fels, Vogelherd, and Geißenklösterle in southwestern Germany, highlighted the absence of a specialized group of tools. A wide range of resources was exploited by a wide range of mainly hand-held tool types (Hardy et al. 2008). At Grotte de l'Observatoire, two endscrapers were heavily used to process hard animal material, according to Porraz et al. (2010). Carinated endscrapers from the Aurignacian levels of the Le Flageolet rock shelter were secondarily used to work bone and antler when exhausted as cores. (Hays and Lucas 2000).

Carinated endscrapers Initially classified as items used for scraping or engraving by the first typologists, these artifacts, typical of Upper Paleolithic industries, have mainly been studied in recent years using a functional approach to assess their exact meaning in lithic assemblages (Domingo et al. 2012; Hardy et al. 2008; Le Brun-Ricalens et al. 2006). It has long been recognized that Aurignacian lithic technology is characterized, among other things, by the presence of carinated pieces, in particular endscrapers and burins. Given the scarcity of analysis on Aurignacian lithic tools, their function is still debated. Hays and Lucas (2000), who examined burins and scrapers from the Aurignacian layers of Le Flageolet (France), proposed that these pieces were meant as specific cores for the production of Dufour bladelets and occasionally used as tools only at the end of the production sequence. However, other studies (e.g., Dinnis et al. 2009) demonstrated an actual use of carinated forms highlighting the great variability of tool functions in the past. Given the correlation between carinated implements and bladelets in several Aurignacian sites, this hypothesis must be considered. The evidence from Fumane supports this view. Microscopic and technological observations of the carinated endscrapers from units A and D confirm their use as bladelet cores. Specifically, small bladelets with curved profiles were produced and subsequently modified into bladelets with convergent or lateral retouch (Falcucci et al. 2017, 2018). No evidence of use was observed on the alleged working edge of the pieces.

\section{Endscrapers in late Middle Paleolithic and early Upper Paleolithic of Europe}

In the complex ensemble of innovations in the cultural framework of the EUP, several aspects have to be taken into account when assessing the significance of a stone tool type that proves to be as specialized as the endscraper. 
Do endscrapers mark a novelty in post-Mousterian assemblages? "Il existe, dans le Paléolithique inférieur et moyen, une variété surprenante de types de grattoirs, bien que, pris dans leur ensemble, ces outils arrivent rarement à former un pourcentage important." With these words, Francois Bordes, in 1961, commented on the anecdotal presence of endscrapers in the Lower and Middle Paleolithic industries of Europe, leading him to reduce refinements in the descriptive criteria of the variability of Upper Paleolithic tools in his typology (Bordes 1961). Numerous reports on the composition of Middle Paleolithic toolkits mention the presence of retouched fronts placed at the apex of simple, double or convergent scrapers of flakes or blades, with frontal, naillike types, or carinated types like in the Quina Mousterian. The scraper-head should take its shape, thus, as a result of invasive retouching usually started from one side of the tool, rather than from a clear design with the goal of making an endscraper.

Endscrapers, thus, result from a deliberate design starting from the MP-UP transition. Despite their marked presence in the Châtelperronian, the Uluzzian, the Bohunician, and other industries (see references below), these tools have, unfortunately, only rarely been studied.

The Châtelperronian is the most representative EUP industry of Western Europe, geographically distributed in southwestern France and northern Spain (Pelegrin and Soressi 2007). In this technocomplex, the main aim of lithic knapping is the production of regular blades for specific points, whereas blanks deviating from the required metric and technical standards were shaped into other types of tools (Roussel 2013), with endscrapers being the most numerous. Endscrapers were manufactured on blanks selected among large and elongated flakes (Bachellerie 2011; Baillet et al. 2014; Roussel 2011). Large flakes equipped with a semi-circular scraper-head are considered diagnostic of this complex, as they have been documented at several sites under different names such as "circular," "discoid," "circular arc," or "large front" endscraper (see Arambourou and Jude 1964; Connet 2002; Delporte 1953; Leroi-Gourhan and Leroi-Gourhan 1964; Pelegrin 1995; Pradel 1959, 1961; de Sonneville-Bordes 2002). On these objects, retouching shaped the front in continuity with the adjacent edges with a consistent degree of invasiveness (Roussel et al. 2016). At Quinçay, several endscrapers were made on large laminar rejuvenation flakes (length range 1.2 to $5.8 \mathrm{~cm}$ and 4 to $9 \mathrm{~cm}$ in width; Roussel et al. 2016). The only functional data currently available on Châtelperronian endscrapers are from a small sample found at the open-air site Canaule II (Creysse, Dordogne, France; Bachellerie 2011). This study has revealed that, despite their great morphological variability, all the endscrapers with reliable evidence of use have been used for scraping dry hide. Use-wear traces have a limited distribution on the scraper-head, with no traces of use or hafting observable on the lateral edges, suggesting little technological investment (Bachellerie 2011; Baillet et al. 2014).

The Uluzzian was originally identified in central-southern Italy but is also found in northern Italy and in the south of the Balkans (Douka et al. 2014; Kaczanowska et al. 2010; Moroni et al. 2013; Palma di Cesnola 1989; Peresani et al. 2016, 2019a, b). This technocomplex is characterized by the production of flakes and laminar flakes in addition to small blades and bladelets, with a toolkit composed of convex backed pieces and crescents, splintered pieces, denticulates, scrapers, endscrapers, truncations, retouched blades, and bladelets (Moroni et al. 2013; Peresani 2014). Generally, endscrapers are scarcely represented in Uluzzian lithic assemblages and make up less than 5\% of the total amount of retouched tools. However, at Cavallo Cave, these tools have been reported in large numbers and represent the most abundant tool type (42.7\%; Moroni et al. 2018) in layer EIII, previously assigned by A. Palma di Cesnola to the Archaic Uluzzian (Palma di Cesnola 1989). At Castelcivita Cave, endscrapers have primarily been found in levels a to $f$ (included in sub-layers rsa, rpi, pie) and are made on flakes, with short types with unretouched lateral edges being the most predominant. The typological range of endscrapers also includes nosed or frontal carinated forms, or others on flake with an additional retouched side or an opposed pole modified by splintering (Gambassini 1997). At Cavallo, these artifacts are mostly characterized by semicircular scraperheads and are made on thin slabs of siliceous limestone (lastrine), naturally fragmented or deliberately shortened by retouching the pole opposed to the scraper-head. Retouch extends from the front to the sides on only a few specimens. Maximum sizes are generally short as a result of a deliberate design (Moroni et al. 2018). Riparo Broion, in the north of Italy, is another Uluzzian site with endscrapers. In total, six endscrapers are present, nosed and shouldered types, manufactured on wide and thin flakes (Peresani et al. 2019a, b). At Fumane, the Uluzzian layer A3 yielded only one endscraper made on a cortical flake that was extensively thinned on its ventral face opposite to the scraper-head (Peresani et al. 2016). Additionally, the tools recorded at La Fabbrica Cave and Colle Rotondo were made on short thick flakes. One from La Fabbrica preserves traces of hafting adhesive on the lateral side (Villa et al. 2018). Further information on the technology and function of these tools is not available.

Endscrapers are a key component of the retouched tool equipment in Bohunician assemblages in Central Europe (Škrdla 2017; Svoboda 2003). However, data on these artifacts are still poor and limited to typology. Blanks range from cortical and non-cortical flakes to Levallois flakes and Levallois points, blades (cortical, non-cortical, and crested), and thin flakes (Škrdla 2017). Detailed information is available from Stránská-Skála, where endscrapers are the most 
numerous type of tool made on flat unretouched blades and flakes. Some of these have lateral retouch. The scraperheads are mostly frontal type, but nail or nosed types are also present (Svoboda 2003). Further, Stránská-Skála is the only source of information on the function of endscrapers in the Bohunician. Tools from Stránská-Skála III, 1982, and from Stránská-Skála IIIa, 1984, revealed correspondence between the number of scraper-heads and the actually used areas (AUAs) and hide working performed with transversal motion using a very uniform angle of the used edge (57-89 aver. $70.5^{\circ}$ ). Only one tool bears probable traces of hafting (Šainerová 2003).

From the data abovementioned, it clearly emerges that the systematic adoption of endscrapers is a shared trait of EUP assemblages. Despite the variability in types, size, and shapes in which they occur, endscrapers were a regular component of the toolkit in the traditions preceding the Protoaurignacian and the Aurignacian.

\section{Conclusion}

The results of this integrated techno-functional study shed light on a standardized class of stone tools that are present across Upper Paleolithic technocomplexes but have been neglected in past research.

Endscrapers from the Protoaurignacian layers A2 and A1 and the late Protoaurignacian layers of macro-unit D of Fumane Cave are characterized by a marked techno-morphological and functional homogeneity, while no evolutionary trend across the sequence has been noticed in terms of type or function. In most cases, both laminar products and flakes were regularly selected and transformed into endscrapers by retouching, with only one exception. Despite the high morpho-metrical variability of the blanks, we highlighted a trend in the selection of blanks with suitable attributes (regular shape, reduced thickness, slightly curved profile). However, we were unable to isolate a possible set of features diagnostic to the design of the Protoaurignacian endscraper. Macro- and micro-wear analyses underlined that endscrapers primarily functioned as hide working tools, in the hand or most often while inserted into a haft, for different hide processing stages. Our results emphasize the high potential of these tools for reconstructing past activities and behaviors through detailed functional analyses.

Based on the available information, endscrapers from EUP sites have shown different kinds of uses that range from working hides to working hard animal materials (bone, antler) and, to a limited extent, possibly also wood. At Fumane, the endscrapers were exclusively used for hide working and this for different stages in the hide working process. Our study raises questions about the exact tasks, within the context of hide working, these tools were set to; an issue that is yet to be addressed and will certainly guide and inspire future works. While certain scraper-head morphologies were a consequence of incomplete resharpening, at this stage, we can only postulate the functional correlation between other scraper-head morphologies (convex, oblique) and specific processing tasks, or hafting arrangements. A more detailed use-wear analysis that also integrates specific hypothesis testing through experimentation, inspired by relevant ethnographic studies (e.g., Beyries and Rots 2008, 2011; Sahle et al. 2012; Shott and Weedman 2007; Weedman 2002, 2006), will provide a better understanding of the exact technological and functional choices.

The Fumane endscrapers are essentially different in terms of their frequency, morphology, and in the fact that many of them were used hafted in comparison with other EUP technocomplexes. The high frequency of end-products and other regular laminar by-products used as blanks for single endscrapers that feature our assemblage appears to be a common trait shared by all Protoaurignacian industries. Carinated forms that generally spread during later stages of the Aurignacian are rare at Fumane, and only show a slight increase in their frequency in the late Protoaurignacian layers (Falcucci et al. 2020). However, our case study demonstrates that systematic use-wear analysis is required to assess their function as tools.

To conclude, this study confirms that the endscraper was already a task-oriented domestic tool in the early phase of the Upper Paleolithic. The tools' functional specialization we highlighted necessarily implies a direct connection with a request for hides among Upper Paleolithic hunter-gatherers for personal and/or group use, regardless of their cultural context. The use of animal skins roots long back in the Paleolithic time to indicate a continuous need for equipment or for protecting and thermally isolating bodies, regardless of the latitude position of the settled regions. Nonetheless, the advent of the Upper Paleolithic coincides with an increase in the composition of the toolkit used for tanning, treating, and finalizing skins and furs removed from a wide variety of herbivore and carnivore preys. The morpho-functional standardization to which endscraper working edges were subjected reflects a template shared between groups at the continental scale, aside from the many variants raised in relation to the specific cultural background or the ecological condition. The spreading of the endscrapers in the earliest Upper Paleolithic cultures also coincides with the systematic use of awls and needles. Awls were a stable component of the Châtelperronian and Aurignacian bone tool industries in Western Europe like at Grotte du Renne, France (d'Errico et al. 2003; Julien et al. 2019). Furthermore, comparable tools were also described in different Uluzzian sites in southern Europe (d'Errico et al. 2012). Uluzzian bone tools were made from limbs of red deer 
and horses, while reindeer, horse, and, occasionally, carnivore long bones were exploited in the Châtelperronian. Their use like perforators of soft tissues like fresh skins and furs (d'Errico et al. 2003, 2012) has recently been revealed also for a set of awls discovered at Bacho Kiro Cave, Bulgaria, in the $47 \mathrm{ky}$ cal BP old IUP contest, which predates of a few thousand years the appearance of the Châtelperronian and Uluzzian technocomplexes (Higham et al. 2014; Hublin et al. 2020). Given the certain attribution of the initial Upper Paleolithic assemblage to the first introgression of AMH in Europe, this chronological setting consolidates previous suggestions that the adoption of comparable awl-based bone industries results from a trans-cultural diffusion (Hublin et al., 2020). Sewing firstly appears as an original innovation at the onset of the Upper Paleolithic. The lack of evidence in Europe is counterbalanced by findings in Siberia and Caucasus associated with blade-based lithic technology of the EUP (d'Errico et al. 2018). Although needles are more sophisticated tools than awls, both foster our inference that clothes (Collard et al. 2016), as well as bags and other portable containers, were manufactured.

Furthermore, during this long period, a combination of economic and cultural grounds supports the ensemble of morpho-technical changes we observe across the cultures, especially from the middle to the late phase of the Upper Paleolithic. Endscapers were not spared from this process (Peresani et al. 2014), and they do not deviate from their main functional purpose tied to the processing and treatment of hide and fur. The challenge of future integrated techno-functional applications in the examination of tool assemblages stands in the refinement of hide and fur processing in consideration with the evolution of endscrapers throughout the Upper Paleolithic and Mesolithic.

Supplementary Information The online version contains supplementary material available at https://doi.org/10.1007/s12520-021-01367-4.

Acknowledgements Research and fieldwork at Fumane is coordinated by the Ferrara University (MP) in the framework of a project supported by the Ministry of Culture-SAPAB Archaeological Superintendence, public institutions (Lessinia Mountain Community-Regional Natural Park, B.I.M. Adige, Fumane Municipality), Foundations (Leakey Foundation, Spring 2015 Grant), and private associations and companies. The research of V. Rots is supported by the Fund for Scientific Research (FNRS) and the European Research Council (ERC starting grant; Agreement Nr. 312283). The technological study of unit D was conducted by A. Falcucci thanks to a research grant from the University of Ferrara under the supervision of M. Peresani. The research of A. Falcucci is supported by the Deutsche Forschungsgemeinschaft (DFG) under grant agreement no. 431809858 (FA 1707/1-1). The authors are grateful to a team of students for organizing the lithic collections in 2015 and to Noora Taipale, Sonja Tomasso, and Dries Cnuts from the TraceoLab team (University of Liège) for their assistance during the analysis, and to Gabriele Ghinamo and Gillian Wong for editing the English text.
Author contribution M. P. designed research; A. A., R. D., and A. F. analyzed morphometric and technological data; A. A. and V. R. analyzed functional data; all authors wrote and edited the manuscript.

Funding Open access funding provided by Università degli Studi di Ferrara within the CRUI-CARE Agreement.

Open Access This article is licensed under a Creative Commons Attribution 4.0 International License, which permits use, sharing, adaptation, distribution and reproduction in any medium or format, as long as you give appropriate credit to the original author(s) and the source, provide a link to the Creative Commons licence, and indicate if changes were made. The images or other third party material in this article are included in the article's Creative Commons licence, unless indicated otherwise in a credit line to the material. If material is not included in the article's Creative Commons licence and your intended use is not permitted by statutory regulation or exceeds the permitted use, you will need to obtain permission directly from the copyright holder. To view a copy of this licence, visit http://creativecommons.org/licenses/by/4.0/.

\section{References}

Abu-Zeid N, Russo P, Bignardi S, Peresani M (2019) Deep in a Paleolithic archive: integrated geophysical investigations and laserscanner reconstruction at Fumane Cave. Italy J Archaeol Sci: Reports 27:101276. https://doi.org/10.1016/j.jasrep.2019.101976

Anderson L, Chesnaux L, Rué M, Picavet R, Fernandes P, Morala A, Caux S, Tallet P, Caverne JB, Kawalek E (2016) Regards croisés sur la station aurignacienne de Brignol (Villeneuve-sur-Lot, Lotet-Garonne, France). Paléo 27:11-42

Anderson L, Lejay M, Brugal JP, Costamagno S, Heckel C, Araujo Igreja M, de Pradeau JV et al (2018) Insights into Aurignacian daily life and camp organization: the open-air site of Régismontle-Haut. Quat Int 492(30):69-98. https://doi.org/10.1016/j. quaint.2018.04.034

Andrefsky W (1994) Raw-material availability and the organization of technology. Am Antiq 59:21-34

Andrefsky W (1997) Thoughts on stone tool shape and inferred function. J Middle Atlantic Archaeol 13:125-143

Andrefsky W (1998) Lithics: macroscopic approaches to analysis. Cambridge University Press, Cambridge, UK

Arambourou R, Jude PE (1964) Le Gisement de la Chèvre à Bourdeilles (Dordogne). Imprimerie Magne, Périgueux.

Bachellerie F (2011) Quelle unité pour le Châtelperronien? Apport de l'analyse taphonomique et techno-économique des industries lithiques de trois gisements aquitains de plein air: le Basté, Bidart (Pyrénées-Atlantiques) et Canaule II (Dordogne). Ph.D. Dissertation, University of Bordeaux I.

Bachellerie F, Bon F, Deschamps M, Eizenberg L, Henry-Gambier D, Mourre V, Normand C, Pelegrin J, Primault J, Scandiuzzi R, Thiébaut C (2011) Archaeological signatures of hunting activities applied to comparisons of Mousterian, Chatelperronian and Aurignacian industries in the Pyrenees: the nature of hunting tools and site functions. In: Bon Fr, Costamagno S, Valdeyron $\mathrm{N}$ (eds) Hunting Camps in Prehistory. Current Archaeological Approaches, Proceedings of the International Symposium, May 13-15 2009, University Toulouse II - Le Mirail, P@ lethnology 3, pp 131-167.

Baillet M, Bachellerie F, Bordes JG (2014) Enquête autour d'un outil: approche techno-économique, fonctionnelle, et expérimentale des grattoirs châtelperroniens de Canaule II (Creysse, Dordogne, France). Paléo 25:7-36 
Bamforth DB (1986) Technological efficiency and tool curation. Am Antiq 51:38-50

Bar-Yosef O (2002) The Upper Paleolithic revolution. Annu Rev Anthropol 31:363-393. https://doi.org/10.1146/annurev.anthro. 31.040402 .085416

Bertola S, Broglio A, Cristiani E, De Stefani M, Gurioli F, Negrino F, Romandini M, Vanhaeren M (2013) La diffusione del primo Aurignaziano a sud dell' arco alpino. Preistoria Alpina 47:17-30

Beyries S, Cattin MI (2015) Resharpening and recycling: different conceptions of the Magdalenian tools. Quat Int 361:260-268. https:// doi.org/10.1016/j.quaint.2014.07.042

Beyries S, Rots V (2008) Méthodes de reconstruction des procédés de traitement des peaux en préhistoire: Premières applications archéologiques. In: Audouze F, Enloe J, Zubrow E (eds) Unraveling Domesticity, Cambridge University Press.

Beyries S, Rots V (2011) The contribution of ethno-archaeology and macro and microscopic wear traces to the understanding of archaeological hide-processes. In: Zubrow E, Audouze F, Enloe J (eds) The Magdalenian Household: Unraveling Domesticity, SUNY press.

Blades BS (2003) End scraper reduction and hunter-gatherer mobility. Am Antiq 68(1):141-156

Bon F (2002) L'Aurignacien entre mer et océan : réflexion sur l'unité des phases anciennes de l'Aurignacien dans le sud de la France. Société Préhistorique Française, Mémoires, XXIX, Paris.

Bordes F (1961) Typologie du Paléolithique ancien et moyen. Delmas, Bordeaux.

Broglio A, Bertola S, De Stefani M, Gurioli F (2006) Le strutture d'abitato aurignaziane della Grotta di Fumane. Dialektikê, Cahiers de Typologie analytique (Servei d'Investigacions Arquerlògiques i Prehistòriques): 27-43.

Broglio A, Cremaschi M, Peresani M, Bertola S, Bolognesi L, De Stefani M, Fiocchi C, Gurioli F, Marini D (2003) L'Aurignacien dans le territoire préalpin: la Grotte de Fumane. In: Vasilev SA, Soffer O, Kozlowski JK (eds) Perceived landscapes and built environments. The cultural geography of Late Palaeolithic Eurasia, vol. 1122, British Archaeological Reports, International Series: 93-104.

Broglio A, Dalmeri G (2005) Pitture paleolitiche nelle Prealpi Venete: Grotta di Fumane e Riparo Dalmeri Verona, Italy: Mem. Verona, Sezione Scienze dell'Uomo.

Broglio A, De Stefani M, Gurioli F, Pallecchi P, Giachi G, Higham T, Brock F (2009) The decoration of Fumane Cave in the picture of the Aurignacian art. L'anthropologie 113(5):753-761

Caricola I, Zupancich A, Moscone D, Mutri G, Falcucci A, Duches R, Peresani M, Cristiani E (2018) Exploring Early Upper Palaeolithic knapping techniques and gestures. Use wear and spatial analyses applied to the study of macro-lithic tools. PLoS ONE 13(12): e0207773. https://doi.org/10.1371/journal.pone. 0207773

Cavallo G, Fontana F, Gialanella S, Gonzato F, Riccardi MP, Zorzin R, Peresani M (2018) Heat treatment of mineral pigment during Upper Palaeolithic in North-Eastern Italy. Archaeometry 60(5):1045-1061. https://doi.org/10.1111/arcm.12360

Cavallo G, Fontana F, Gonzato F, Peresani M, Riccardi MP, Zorzin R (2017) Textural, microstructural and compositional characteristics of Fe-based geomaterials and Upper Palaeolithic ocher in the Lessini Mountains, Northeast Italy: implications for provenance studies. Geoarchaeology 32(4):437-455. https://doi. org/10.1002/gea.21617

Cnuts D, Peresani M, Purdue L, Porraz G, Soressi M, Tomasso A, Val A, Rots V (2018) Assessing residue preservation and identification on stone tool assemblages from four different Late Pleistocene sites. In: Beyries S, Hamon C, Maigrot Y (eds) AWRANA 2018. Beyond use-wear traces: tools and people.
Bulletin du Musée d'Anthropologie Préhistorique de Monaco $58, \mathrm{pp} 42$.

Collard M, Tarle L, Sandgathe D, Allan A (2016) Faunal evidence for a difference in clothing use between Neanderthals and early modern humans in Europe. J Anthropol Archaeol 44:235-246. https://doi.org/10.1016/j.jaa.2016.07.010

Collin F, Jardon-Giner P (1993) Travail de la peau avec des grattoirs emmanchés. Réflexions sur des bases expérimentales et ethnographiques. In: Traces et fonctions: les gestes retrouvés. Actes du colloque international de Liège, 8-9-10 décembre 1990, vol. 2, ERAUL, Liège, pp 105-117.

Connet N (2002) Le Châtelperronien: réflexions sur l'unité et l'identité techno-économique de l'industrie lithique. L'apport de l'analyse diachronique des industries lithiques des couches châtelperroniennes de la grotte du Renne à Arcy-sur-Cure (Yonne). Ph.D. Dissertation, University of Lille 1.

d'Errico F, Borgia V, Ronchitelli A (2012) Uluzzian bone technology and its implications for the origin of behavioural modernity. Quat Int 259:59-71. https://doi.org/10.1016/j.quaint.2011.03.039

d'Errico F, Doyon L, Zhang S, Baumann M, Lázničková-Galetová M, Gao X, Chen F, Zhang Y (2018) The origin and evolution of sewing technologies in Eurasia and North America. J Hum Evol 125:71-86. https://doi.org/10.1016/j.jhevol.2018.10.004

d'Errico F, Julien M, Liolios D, Vanhaeren M, Baffier D (2003) Many awls in our argument. Bone tool manufacture and use in the Châtelperronian and Aurignacian levels of the Grotte du Renne at Arcy-sur-Cure. In: Zilhão J, d'Errico F (eds) The Chronology of the Aurignacian and of the Transitional Technocomplexes. Dating, Stratigraphies, Cultural Implications. Instituto Português de Arqueologia, Lisbon, pp 247-270.

de Sonneville-Bordes D (2002) Les industries du Roc-de-Combe (Lot). Périgordien Et Aurignacien Préhistoire Du Sud-Ouest 9:121-161

de Sonneville-Bordes D, Mortureux B (1955) L'abri Caminade, commune de La Canéda (Dordogne). Bull Soc Prehist Fr 52(9):608-619

De Stefani M, Dini M, Klempererova H, Peresani M, Ranaldo F, Ronchitelli A, Ziggiotti S (2012) Continuity and replacement in flake production across the Middle-Upper Paleolithic transition: a view over the Italian Peninsula. In: Pastoors A, Peresani M (eds) Flakes not blades: the role of flake production at the onset of the upper paleolithic in Europe, vol. 5, Mattmann: Wissenschaftliche Schriften des Neanderthal Museums, pp 75-91.

Delporte H (1953) Une série inédite de pièces de Châtelperron. La Physiophile 29:23-28

Dibble HL (1997) Platform variability and flake morphology: a comparison of experimental and archeological data and implications for interpreting prehistoric lithic technological strategies. Lithic Technol 22:150-170. https://doi.org/10.1080/01977261.1997. 11754540

Dinnis R (2008) On the technology of late Aurignacian burin and scraper production, and theimportance of the Paviland lithic assemblageand the Paviland burin. Lithics: The Journal of the Lithic Studies Society 29: 18-35.

Dinnis R, Pawlik A, Gaillard C (2009) Bladelet cores as weapon tips? Hafting residue identification and micro-wear analysis of three carinated burins from the late Aurignacian of Les Vachons. France J Archaeol Sci 36(9):1922-1934. https://doi.org/10. 1016/j.jas.2009.04.020

Djindjan F, Kozlowsky J, Otte M (1999) Le Paléolithique supérieur en Europe. Armand Colin, Paris

Domingo R, Mazo C, Utrilla P (2012) Hunting camps and nucleiform endscrapers in the Cantabrian Lower Magdalenian: a lithic microwear analysis. Quat Int 272-273:105-110. https://doi.org/ 10.1016/j.quaint.2012.03.027 
Donahue RE, Fischer A (2015) A Late Glacial family at Trollesgave, Denmark. J Archaeol Sci 54:313-324. https://doi.org/10.1016/j. jas.2014.12.018

Douka K, Higham T, Wood R, Boscato P, Gambassini P, Karkanas P, Peresani M, Ronchitelli AM (2014) On the chronology of the Uluzzian. J Hum Evol 68:1-13. https://doi.org/10.1016/j.jhevol. 2013.12.007

Falcucci A (2018) Towards a renewed definition of the Protoaurignacian. Mitteilungen Der Gesellschaft Für Urgeschichte 27:87-130

Falcucci A, Conard NJ, Peresani M (2017) A critical assessment of the Protoaurignacian lithic technology at Fumane Cave and its implications for the definition of the earliest Aurignacian. PLoS ONE 12(12):e0189241. https://doi.org/10.1371/journal.pone.0189241

Falcucci A, Conard NJ, Peresani M (2020) Breaking through the Aquitaine frame: a re-evaluation on the significance of regional variants during the Aurignacian as seen from a key record in southern Europe. J Anthropol Sci 98:99-140. https://doi.org/10. 4436/JASS. 98021

Falcucci A, Peresani M (2018) Protoaurignacian core reduction procedures: blade and bladelet technologies at Fumane Cave. Lithic Technol 43:125-140. https://doi.org/10.1080/01977261.2018. 1439681

Falcucci A, Peresani M, Roussel M, Normand C, Soressi M (2018) What's the point? Retouched bladelet variability in the Protoaurignacian. Results from Fumane, Isturitz, and Les Cottés. Archaeol Anthropol Sci: 4-18. https://doi.org/10.1007/ s12520-016-0365-5

Frison G (1968) A functional analysis of certain chipped stone tools. Am Antiq 33:149-155

Fu Q, Posth C, Hajdinjak M, Petr M, Mallick S, Fernandes D, Furtwängler $\mathrm{A}$, Haak W, Meyer M et al (2016) The genetic history of Ice Age Europe. Nature 534(7606):200-205. https://doi.org/ 10.1038/nature17993

Gambassini P (ed) (1997) Il Paleolitico di Castelcivita. Culture e Ambiente. Electa, Materiae, Napoli: 5.

Hardy BL, Bolus M, Conard NJ (2008) Hammer or crescent wrench? Stone-tool form and function in the Aurignacian of southwest Germany. J Hum Evol 54(5):648-662. https://doi.org/10.1016/j. jhevol.2007.10.003

Hays MA, Lucas G (2000) A technological and functional analysis of carinates from Le Flageolet I, Dordogne, France. J Field Archaeol 27:455-465. https://doi.org/10.1179/jfa.2000.27.4.455

Higham T, Brock F, Peresani M, Broglio A, Wood R, Douka K (2009) Problems with radiocarbon dating the Middle to Upper Palaeolithic transition in Italy. Quat Sci Rev 28(13-14):1257-1267. https://doi.org/10.1016/j.quascirev.2008.12.018

Higham T, Douka K, Wood R, Ramsey C, Brock F, Basell L, Camps M, Arrizabalaga A, et al (2014) The timing and spatiotemporal patterning of Neanderthal disappearance. Nature 512; https://doi. org/10.1038/nature13621

Hublin JJ, Sirakov N, Aldeias V, Bailey S, Bard E, Delvigne V, Endarova E et al (2020) Initial Upper Palaeolithic Homo sapiens from Bacho Kiro Cave, Bulgaria. Nature 581:1-4. https://doi.org/ 10.1038/s41586-020-2259-Z

Inizan ML, Reduron M, Roche H, Tixier J (1995) Technologie de la pierre taillée. Préhistoire de la pierre taillée Meudon: CREP.

Jacquier J, Naudinot N (2015) Socio economic significance of stone tools recycling, reuse and maintenance at the end of the Lateglacial in Northwestern France. Quat Int 361:269-287. https://doi. org/10.1016/j.quaint.2014.09.051

Jardon-Giner P, Sacchi D (1994) Traces d'usage et indices de réaffûtages et d'emmanchements sur des grattoirs magdaléniens de la grotte Gazel à Sallèles-Cabardes (Aude, France). L'anthropologie 98:427-446

Jéquier C, Peresani M, Livraghi A, Romandini M (2018) Same but different: 20,000 years of bone retouchers from Northern Italy.
A diachronologic approach from Neanderthals to Anatomically Modern Humans. In: Hutson JM, García-Moreno A, Noack E, Turner E, Villaluenga A, Gaudzinski-Windheuser S (eds) The Origins of Bone Tool Technologies. Römisch-Germanisches Zentralmuseum - TAGUNGEN. Verlag des Römisch-Germanischen Zentralmuseums, Band 35, pp 269-285.

Julien M, David F, Girard M, Roblin-Jouve A (eds) (2019) Le Châtelperronien de la Grotte du Renne (Arcy-sur-Cure, Ynne, France). Les foulles d'André-Leroi-Gourhan (1949-1963). Paléo, n.s., p 525

Kaczanowska M, Kozłowski JK, Sobczyk K (2010) Upper Palaeolithic human occupations and material culture at Klissoura Cave 1. Eurasian Prehistory 7(2):133-286

Keeley LH (1980) Experimental determination of stone tools uses. University of Chicago Press, Chicago-London, A microwear analysis

Keeley LH, Newcomer MH (1977) Microwear analysis of experimental flint tools: a test case. J Archaeol Sci 4(1):29-62. https://doi.org/ 10.1016/0305-4403(77)90111-X

Kuhn SL, Zwyns N (2014) Rethinking the initial Upper Paleolithic. Quat Int 347:29-38. https://doi.org/10.1016/j.quaint.2014.05.040

Laplace G (1964) Essai de typologie systématique, Università di Ferrara.

Le Brun-Ricalens F (2005) Chronique d'une reconnaissance attendue. Outils "carénés", outils "nucléiformes": nucléus à lamelles. Bilan après un siècle de recherches typologiques, technologiques et tracéologiques. In: Le Brun-Ricalens F (ed) Productions lamellaires attribuées à l'Aurignacien. MNHA, Luxembourg, pp $23-72$.

Le Brun-Ricalens F, Bracco JP, Brou L (2006) Burins carénés, grattoirs carénnés et formes associés: un retournement! In: Agraujo M, Bracco JP, Le Brun- Ricalens F (eds) Burins préhistoriques: formes, fonctionnements, fonctions. Musée National d'histoire et d'art, Luxembourg.

Leroi-Gourhan A, Leroi-Gourhan A (1964) Chronologie des grottes d'Arcy-sur-Cure (Yonne). Gallia Préhistorique 7:1-64

Levi Sala I (1986) Use wear and post-depositional surface modification: a word of caution. J Archeol Sci 13(3):229-244. https://doi. org/10.1016/0305-4403(86)90061-0

Loebel TJ (2013) Endscrapers, use-wear, and Early Paleoindians in Eastern North America. In: Fluted ITE (ed) Gingerich JAM. University of Utah, Point Tradition, pp 315-330

López-García JM, dalla Valle C, Cremaschi M, Peresani M (2015) Reconstruction of the Neanderthal and modern human landscape and climate from the Fumane cave sequence (Verona, Italy) using small-mammal assemblages. Quat Sci Rev 128:1-13. https://doi. org/10.1016/j.quascirev.2015.09.013

Malerba G, Giacobini G (1995) Analisi delle tracce di macellazione in un sito paleolitico. L'esempio del Riparo di Fumane (Valpolicella, Verona). Atti I Convegno Nazionale Archeozoologia, Rovigo, Padusa 1:97-108

Mellars P (2004) Neanderthals and the modern human colonization of Europe. Nature 432(7016):461-465. https://doi.org/10.1038/ nature 03103

Mellars P (2011) The earliest modern humans in Europe. Nature 479(7374):483-485. https://doi.org/10.1038/479483a

Morales JI, Vergès JM (2014) Technological behaviors in Paleolithic foragers Testing the role of resharpening in the assemblage organization. J Archaeol Sci 49(1):302-316. https://doi.org/10. 1016/j.jas.2014.05.025

Moroni A, Boscato P, Ronchitelli A (2013) What roots for the Uluzzian? Modern behaviour in Central-Southern Italy and hypotheses on AMH dispersal routes. Quat Int 316:27-44. https://doi. org/10.1016/j.quaint.2019.11.005

Moroni A, Ronchitelli A, Arrighi S, Aureli D, Bailey SE, Boscato P, Boschin F, Capecchi G et al (2018) Grotta del Cavallo 
(Apulia-Southern Italy). The Uluzzian in the mirror. J Anthropol Sci 96:1-36. https://doi.org/10.4436/jass:96004

Morrow JE (1997) End scraper morphology and use-life: an approach for studying paleoindian lithic technology and mobility. Lithic Technol 22(1):70-85. https://doi.org/10.1080/01977261.1997. 11754534

Odell GH (1977) The application of micro-wear analysis to the lithic component of an entire prehistoric settlement: methods, problems and functional reconstructions. Unpublished $\mathrm{PhD}$ thesis. Department of Anthropology. Harvard University. Ann Arbor.

Palma di Cesnola A (1989) L'Uluzzien: faciès Italien du Leptolithique archaïque. L'anthropologie 93:783-812

Palma di Cesnola A (ed) (2004) Paglicci. L'Aurignaziano e il Gravettiano antico. Grenzi ed., Foggia.

Pelegrin J (1995) Technologie lithique : le Châtelperronien de Roc-deCombe (Lot) et de La Côte (Dordogne). Paris, CNRS, Cahiers du Quaternaire 20: 297 pp.

Pelegrin J, Soressi M (2007) Le Châtelperronien et ses rapports avec le Moustérien. In: Vandermeersch B, Maureille B (eds) Les Néandertaliens. Biologie et cultures. Paris, CTHS, Documents préhistoriques 23, pp 297-309.

Peresani M (2012) Fifty thousand years of flint knapping and tool shaping across the Mousterian and Uluzzian sequence of Fumane cave. Quat Int 247:125-150. https://doi.org/10.1016/j.quaint. 2011.02.006

Peresani M (2014) L’Uluzzien en Italie. In: Otte M (sous la dir) Néandertal/Cro-Magnon. La Rencontre. Editions Errance, Arles, pp 61-80.

Peresani M, Bertola S, Delpiano D, Benazzi S, Romandini M (2019) The Uluzzian in the north of Italy. Insights around the new evidence at Riparo Broion. Archaeol Anthropol Sci 11(7): $3503-$ 3536. https://doi.org/10.1007/s12520-018-0770-z

Peresani M, Cristiani E, Romandini M (2016) The Uluzzian technology of Grotta di Fumane and its implication for reconstructing cultural dynamics in the Middle-Upper Palaeolithic transition of Western Eurasia. J Hum Evol 91:36-56. https://doi.org/10. 1016/j.jhevol.2015.10.012

Peresani M, Forte M, Quaggiotto E, Colonese AC, Romandini M, Cilli C, Giacobini G (2019b) Marine shell exploitation in the Early Upper Palaeolithic. Re-examination of the shell assemblages from Fumane Cave (NE Italy). PaleoAnthropology 2019:64-81

Peresani M, Tomio C, Dalmeri G (2014) Les grattoirs épigravettiens et leur « raccourcissement» durant le Tardiglaciaire en Italie. Reflets d'un changement dans l'économie du débitage. In: Langlais M, Naudinot N, Peresani M (eds) Les groupes culturels de la transition Pléistocène-Holocène entre Atlantique et Adriatique. Séances de la Société préhistorique française Paris, 3, pp 205-220.

Peretto C, Biagi P, Boschian G, Broglio A, De Stefani M, Fasani L, Fontana F, Grifoni R et al (2004) Living-floors and structures from the Lower Palaeolithic to the Bronze Age. Collegium Antropol 28(1):63-88

Porraz G, Simon P, Pasquini A (2010) Identité technique et comportements économiques des groupes proto-aurignaciens à la grotte de l'Observatoire (principauté de Monaco). In: Gallia préhistoire, tome 52, CNRS Editions, Paris, pp 33-59. http://doi.org/https:// doi.org/10.3406/galip.2010.2470

Pradel L (1959) Le Périgordien II de la grotte des Cottés (commune de Saint-Pierre-de-Maillé, Vienne). Bull Soc Prehist Fr 56:421-427

Pradel L (1961) La grotte des Cottés commune de Saint-Pierre-deMaillé (Vienne). Anthropologie 65:229-258

Roebroeks W (2008) Time for the Middle to Upper Paleolithic transition in Europe. J Hum Evol 55:918-926. https://doi.org/10. 1016/j.jhevol.2008.08.008
Romandini M, Crezzini J, Bortolini E, Boscato P, Boschin F, Carrera L, Nannini N, Tagliacozzo A et al (2020) Macromammal and bird assemblages across the Late Middle to Upper Palaeolithic transition in Italy: an extended zooarchaeological review. Quat Int 551:183-223. https://doi.org/10.1016/j.quaint.2019.11.008

Rots V (2002a) Hafting traces on flint tools: possibilities and limitations of macro- and microscopic approaches. Ph.D. Dissertation, Katholieke Universiteit Leuven.

Rots V (2002b) Bright spots and the question of hafting. Anthropologica Et Praehistorica 113:61-71

Rots V (2003) Towards an understanding of hafting: the macro- and microscopic evidence. Antiquity 77:805-815. https://doi.org/10. 1017/S0003598X00061743

Rots V (2005) Wear Traces and the Interpretation of Stone Tools. J Field Archaeol 30(1):61-73. https://doi.org/10.1179/0093469057 91072404

Rots V (2009) The functional analysis of the Mousterian and Micoquian assemblages of Sesselfelsgrotte, Germany. Tool Use and Hafting in the European Late Middle Paleolithic, Quartär 56:37-66

Rots V (2010a) Prehension and hafting traces on flint tools. A methodology. Leuven University Press: 273 pp.

Rots V (2010b) Un tailleur et ses traces. Traces microscopiques de production: programme expérimental et potentiel interprétatif, Bull Soc Royale Belge d'Etudes Géologiques et Archéologiques. Les Chercheurs de la Wallonie, hors-série n 2 : 51-67.

Rots V (2013) Insights into early Middle Palaeolithic tool use and hafting in Western Europe. The functional analysis of Level IIa of the early Middle Palaeolithic site of Biache-Saint-Vaast (France), J Archaeol Sci 40(1): 497-506. https://doi.org/10.1016/j.jas.2012. 06.042

Rots V, Pirnay L, Pirson Ph, Baudoux O (2006) Blind tests shed light on possibilities of interpreting prehistoric stone tool prehension and hafting. J Archaeol Sci 33:935-952. https://doi.org/10. 1016/j.jas.2005.10.018

Rots V, Pirnay L, Pirson Ph, Baudoux O, Vermeersch PM (2001) Experimental hafting traces. Identification and Characteristics Notae Praehistoricae 21:129-137

Roussel M (2011) Normes et variations de la production lithique durant le Châtelperronien : la séquence de la Grande-Roche-dela-Plématrie à Quinçay (Vienne). Ph.D. Dissertation, University of Paris Ouest-Nanterre.

Roussel M (2013) Méthodes et rythmes du débitage laminaire au Châtelperronien : comparaison avec le Protoauignacien. C.R. Palevol 12:233-241

Roussel M, Soressi M, Hublin JJ (2016) The Châtelperronian conundrum: Blade and bladelet lithic technologies from Quinçay, France. J Hum Evol 95:13-32. https://doi.org/10.1016/j.jhevol. 2016.02.003

Rutkoski AR, Miller GL, Maguire L, Eren MI, Bebber MR (2020) The effect of heat on lithic microwear traces: an experimental assessment. Lithic Technol 45:38-47. https://doi.org/10.1080/ 01977261.2019.1690617

Sahle Y, Negash A, Braun DR (2012) Variability in ethnographic hidescraper use among the Hadiya of Ethiopia: implications for reduction analysis. Afr Archaeol Rev 29:383-397. https://doi. org/10.1007/s10437-012-9114-Z

Šainerová A (2003) Use-wear analysis. In: Svoboda JA, Bar-Yosef O (eds) Stránská skála. Origins of the Upper Paleolithic in the Brno Basin, Moravia, Czech Republic. American School of Prehistoric Research Bulletin, 47. Peabody Museum of Archaeology and Ethnology, Harvard University, Cambridge, Massachutsetts, pp 167-171.

Schiffer MB, Downing TE, McCarthy M (1981) Waste not, want not : an ethnoarchaeological stufy of reuse in Tucson, Arizona. In: 
Gould RA, Schiffer MB (eds) Modern Material Culture: The Archaeology of Us. Academic Press, New York, pp 67-86

Semenov SA (1964) Prehistoric technology. An experimental study of the oldest tools and artifacts from traces of manufacture and wear. Cory, Adams \& Mackay, London.

Shott M (1995) How much is a scraper? Curation, Use Rates, and the Formation of Scraper Assemblages. Lithic Technol 20:53-72

Shott MJ, Weedman KJ (2007) Measuring reduction in stone tools: an ethnoarchaeological study of Gamo hidescrapers from Ethiopia. J Archaeol Sci 34(7):1016-1035. https://doi.org/10.1016/j.jas. 2006.09.009

Schulte im Walde T (1987) Kratzer oder Kernsteine? Gebrauchsspurenanalysen an den Kielkratzern aus dem Aurignacian-Inventar Breitenbach B. Quartär 37(38):101-107

Škrdla P (2017) Moravia at the onset of the Upper Paleolithic. The Dolní Věstonice Studies 33: 159 pp.

Svoboda JA (2003) Bohunician and aurignacian typology at Stránská skála. In: Svoboda JA, Bar-Yosef O (eds) Stránská skála. Origins of the Upper Paleolithic in the Brno Basin, Moravia, Czech Republic. American School of Prehistoric Research Bulletin, 47. Peabody Museum of Archaeology and Ethnology, Harvard University, Cambridge, Massachutsetts, pp 153-165.

Tagliacozzo A, Romandini M, Fiore I, Gala M, Peresani M (2013) Animal exploitation strategies during the Uluzzian at Grotta Fumane (Verona, Italy). In: Clark JL, Speth JD (eds) Zooarchaeology and Modern Human Origins: Human Hunting Behavior during the Later Pleistocene. Vertebrate Paleobiology and Paleoanthropology Series. Dordrecht: 1963 Springer, pp 129-150.

Taipale N (2019) Diverse means to an end: domestic tool hafting in the European Upper Palaeolithic, 9th AnnuAl Meeting of the European Society for the Study of Human Evolution, ESHE 2019, 19-21 September 2019, Liège, Belgium.

Tejero JM (2014) Towards complexity in osseous raw material exploitation by the first anatomical modern humans in Europe: Aurignacian antler working. J Anthropol Archaeol 36:72-92. https:// doi.org/10.1016/j.jaa.2014.08.004

Tejero JM, Grimaldi S (2015) Assessing bone and antler exploitation at Riparo Mochi (Balzi Rossi, Italy): implications for the characterization of the Aurignacian in South-western Europe. J Archaeol Sci 6:59-77. https://doi.org/10.1016/j.jas.2015.05.003
Teyssandier N (2008) Revolution or evolution: the emergence of the Upper Paleolithic in Europe. World Archaeol 40(4):493-519. https://doi.org/10.1080/00438240802452676

Tomáŝková S (2005) What is a burin? Typology, technology, and interregional comparison. J Archaeol Method Th 12(2):79-115. https://doi.org/10.1007/s10816-005-5666-4

Torrence R (1989) Retooling: towards a behavioral theory of stone tools. In: Torrence R (ed) Time, energy, and stone tools. Cambridge University Press, Cambridge, pp 57-66

Tringham R, Cooper G, Odell GH, Voytek B, Whitman A (1974) Experimentation in the formation of edge-damage: a new approach to lithic analysis. J Field Archaeol 1:171-196. https:// doi.org/10.1179/jfa.1974.1.1-2.171

Van Gijn AL (2010) Flint in focus. Lithic biographies in the Neolithic and Bronze Age. Sidestone Press, Leiden

Vaughan PC (1985) Use-wear analysis of flaked stone tools. The University of Arizona Press, Century Collection

Villa P, Pollarolo L, Conforti J, Marra F, Biagioni C, Degano I, Lucejko JJ, Tozzi C et al (2018) From Neandertals to modern humans: new data on the Uluzzian. PLoS ONE 13(5):e0196786. https:// doi.org/10.1371/journal.pone.0196786

Villa P, Roebroeks W (2014) Neandertal demise: an archaeological analysis of the modern human superiority complex. PLoS ONE 9(4):e96424. https://doi.org/10.1371/journal.pone.0096424

Weedman KJ (2002) An Ethnoarchaeological study of stone-tool variability among the Gamo hide workers of southern Ethiopia. In: Beyries S, Audoin-Rouzeau F (eds) Le Travail du Cuir de la Préhistoire. Editions APDCA, Antibes, pp 131-142.

Weedman KJ (2006) An ethnoarchaeological study of hafting and stone tool diversity among the Gamo of Ethiopia. J Archaeol Method Th 13:188-237. https://doi.org/10.1007/s10816-006-9010-4

Publisher's note Springer Nature remains neutral with regard to jurisdictional claims in published maps and institutional affiliations. 